\title{
Review Article \\ Electrical Resistivity of Concrete for Durability Evaluation: A Review
}

\author{
Pejman Azarsa and Rishi Gupta \\ Department of Civil Engineering, University of Victoria, Victoria, BC, Canada \\ Correspondence should be addressed to Rishi Gupta; guptar@uvic.ca
}

Received 17 October 2016; Revised 30 March 2017; Accepted 2 May 2017; Published 31 May 2017

Academic Editor: Gianfranco Palumbo

Copyright (C) 2017 Pejman Azarsa and Rishi Gupta. This is an open access article distributed under the Creative Commons Attribution License, which permits unrestricted use, distribution, and reproduction in any medium, provided the original work is properly cited.

\begin{abstract}
Degradation processes in reinforced concrete structures that affect durability are partially controlled by transport of aggressive ions through the concrete microstructure. Ions are charged and the ability of concrete to hold out against transfer of ions greatly relies on its electrical resistivity. Hence, a connection could be expected between electrical resistivity of concrete and the deterioration processes such as increase in permeability and corrosion of embedded steel. Through this paper, an extensive literature review has been done to address relationship between concrete electrical resistivity and its certain durability characteristics. These durability characteristics include chloride diffusivity and corrosion of reinforcement as these have major influence on concrete degradation process. Overall, there exists an inverse or direct proportional correlation between these parameters. Evaluated results, from measuring the concrete electrical resistivity, can also be used as a great indicator to identify early age characteristics of fresh concrete and for evaluation of its properties, determination of moisture content, connectivity of the micropores, and even condition assessment of in-service structures. This paper also reviews and assesses research concerning the influential parameters such as environmental conditions and presence of steel rebar and cracks on measuring electrical resistivity of concrete. Moreover, concrete resistivity concept, application, and its various measurement techniques are introduced.
\end{abstract}

\section{Introduction}

The durability of concrete is defined as its ability to resist weathering action, chemical attack, abrasion, or any other deterioration process to retain its original form, quality, and serviceability when exposed to harsh environment [1]. To a large extent, it is commonly accepted that concrete durability is governed by concrete's resistance to the penetration of aggressive media. This media may be present in a liquid or gaseous state and that may be transported by various mechanisms such as permeation, diffusion, absorption, capillary suction, and combinations of the items just mentioned. Hence, for concrete in service, a combined action of various media may prevail and mixed modes of transport processes occur. Moreover, there are correlations between transport parameters of concrete and the following durability characteristics: carbonation, sulphate attack, alkali-aggregate reaction, frost resistance, leaching, soft water attack, acid attack, abrasion, chloride ingress, and reinforcement corrosion.
Consequently, the transport of ions through microstructure of concrete plays an important role in the control of concrete durability. When ions are charged, then it is the concrete's ability to withstand transfer of charged ions which is highly dependent upon its electrical resistivity. In this study, since chloride ingress and reinforcement corrosion are reported as major concrete deterioration processes, one of the main concentration areas is on these durability characteristics and their relationship with concrete electrical resistivity.

Over the last few decades, a great deal of attention has been paid to research and development of electrical resistivity measurement techniques as a nondestructive technique (NDT) to evaluate the durability of concrete structures. This method is becoming more popular especially for field evaluations due to its simplicity, rapidness, and cost during test conduction. However, the inclusion of these methods into the standards and guidelines is quite slow. Electrical resistivity has been standardized in 2012 by ASTM C1760 [2] to measure the concrete bulk resistivity and also by AASHTO 
TP 95-11 [3] to quantify the surface resistivity of concrete. However, there is a gap that still exists between the current knowledge and industry practice.

Electrical resistivity is a material property that can be used for various purposes, one of which is to identify early age characteristics of fresh concrete. When the fresh concrete sets and hardens, depercolation (discontinuity) of the capillary pore space leads to an increase in its electrical resistivity. Since electrical current is conveyed by dissolved charged ions flowing into the concrete pore solution, it is a good indicator of concrete pore structures [4]. This pore structure formation at early-ages can define the long-term durability of concrete. In addition, the tensile strength of cementitious materials at early-ages is low and the material is prone to cracking. This initial cracking also serves as a pathway for deleterious materials to ingress into the matrix. This cracking can also be captured by resistivity measurements and thus helps predict the long-term durability of concrete. In addition, electrical resistivity can be used as an index to determine the moisture content and the connectivity of the micropores in the concrete [5].

Several researchers attempted to characterize the effects of various parameters on electrical resistivity measurements. One of the important factors affecting the measurements is environmental conditions such as temperature, rainfall, and relative humidity. During testing, good electrical connection between concrete and electrodes as well as specimen geometry plays a key role in having a reliable measurement. The electrical resistivity measurements are highly influenced by the moisture content of concrete. For instance, when the moisture content is reduced, the resistivity is increased significantly. Therefore, considering all these influencing parameters for on-site resistivity measurements and to make meaningful conclusions is not a simple task.

In this paper, the correlation between electrical resistivity and certain durability characteristics of concrete is discussed. These concrete characteristics include chloride permeability, corrosion rate, and compressive strength. Also, different approaches in the measurement of concrete resistivity including bulk and surface resistivity measurements are presented. This paper reviews the effect of several influencing parameters such as external environment (e.g., temperature) and concrete mixture on the electrical resistivity. In addition, some of bulk and surface resistivity test setups (both of laboratory and field tests) conducted by authors are also presented.

\section{Theoretical Background}

2.1. Concept. Electrical resistivity $(\rho)$ of a material is defined as its capability to withstand the transfer of ions subjected to an electrical field. It is largely dependent on the microstructure properties of concrete such as pore size and shape of the interconnections (i.e., tortuosity) [6]. Specimens with similar degree of water saturation and temperature should be used as both of these factors affect resistivity. Lower permeability results from a finer pore network with less connectivity and eventually leads to higher electrical resistivity. The range spanned by resistivity is one of the greatest of any material property [12]. For concrete, it varies from $10^{6} \Omega \cdot \mathrm{m}$ for oven dried samples to $10 \Omega \cdot \mathrm{m}$ for saturated concrete [13]. Electrical resistivity is the ratio between applied voltage $(V)$ and resulting current $(I)$ multiplied by a cell constant and the electrical current is carried by ions dissolved in the pore liquid $[7,14]$. Thus, it is a geometry independent property and an inherent characteristic of a material, as described in the following $[6,14]$ :

$$
\rho=k \cdot R=k \cdot\left(\frac{V}{I}\right),
$$

where $R$ is the resistance of concrete; $k$ is a geometrical factor which depends on the size and shape of the sample as well as the distance between the probes on the testing device [6]. There are several factors that may affect electrical resistivity of concrete, and they can be divided into two groups: (1) intrinsic factors affecting the electrical resistivity of concrete, such as w/c ratio, aging, and pore structure; (2) factors affecting the resistivity measurements, including specimen geometry, moisture content, temperature, electrode spacing, and presence of rebar. For instance, more pore water as well as wider pores results in lower concrete resistivity and environmental factors such as higher temperature decreases the resistivity values [7]. Furthermore, adding reactive supplementary cementitious materials such as blast furnace slag and fly ash leads to lower permeability and higher electrical resistivity due to reduction in capillary porosity and hydroxyl ions $\left(\mathrm{OH}^{-}\right)$. Both carbonation and chloride penetration also individually cause an increase in concrete resistivity in particular in Portland cement concrete but penetrated chloride impact is relatively small [7]. The effects of the abovementioned parameters will be discussed in detail later in this paper.

2.2. Measurement Techniques. Electrical resistivity measurements can be performed in several ways nondestructively: using electrodes positioned on a specimen surface, or placing an electrode-disc or linear array or a four-probe square array on the concrete's surface. Types of device techniques that can be used typically to measure resistivity physically include (1) bulk electrical resistivity test, (2) surface disc test, (3) Wenner four-point line array test, and (4) four-probe square array test.

2.2.1. Bulk Electrical Resistivity Test. In the bulk resistivity method (or uniaxial method), two electrodes are placed on the concrete surface (usually two parallel metal plates) with moist sponge in between (Figure 1(a)). Generally, only standard cylinders/prismatic specimens or cores taken from existing structures are used in this method. The geometrical factor in this method can be obtained by the following equation:

$$
k=\frac{A}{L},
$$

where $A$ is the cross-sectional area perpendicular to the current and $L$ is the height of sample. Although this nondestructive test takes only a few seconds, its application is limited for field evaluation because electrodes access to 


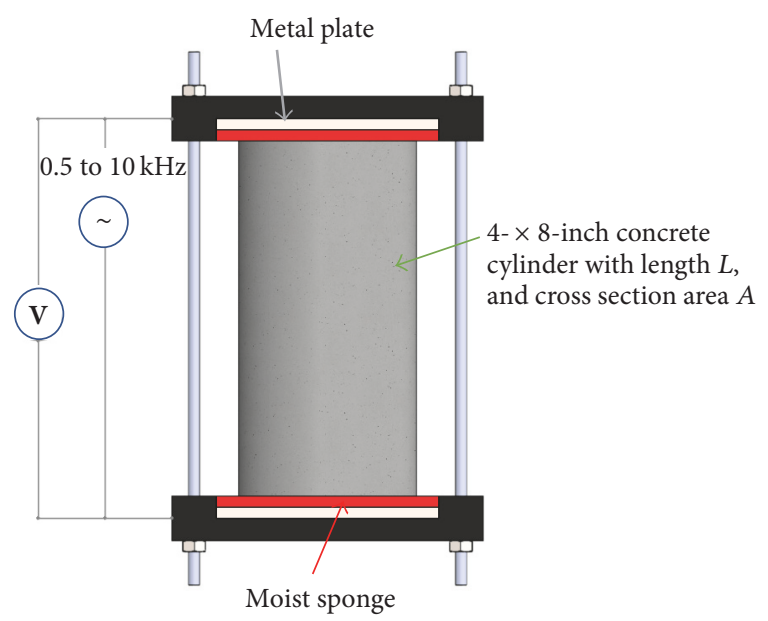

(a)

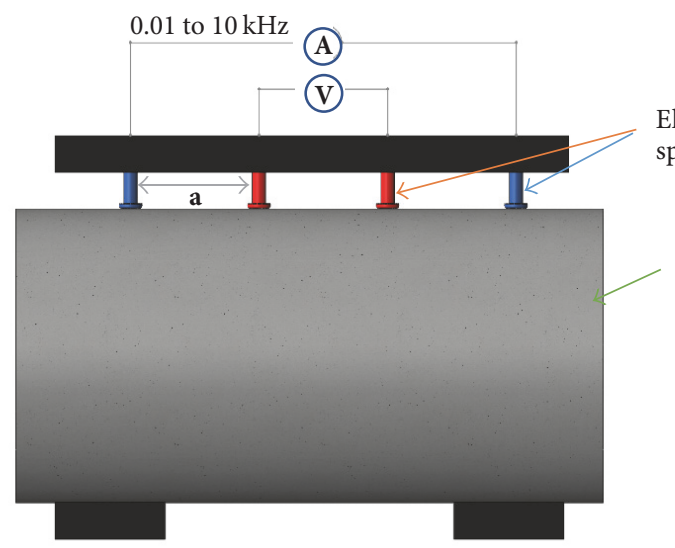

Electrodes spacing $a$

4- $\times 8$-inch concrete cylinder with length $L$, and cross section area $A$

(b)

FIGURE 1: Electrical resistivity measuring techniques: (a) two-point uniaxial method and (b) four-point (Wenner probe) method (reproduced from [6]).

opposite sides of the concrete element is not possible all the time; while other above-mentioned resistivity measurement (surface disc test, Wenner four-point line array test, and fourprobe square array test) methods may use probes placed on only one side surface of specimen.

2.2.2. Surface Disc Test. The electrode-disc test method includes an electrode (disc) placed over a rebar and measuring the resistance between the disc and the rebar, as shown in Figure 2 [7]. One disadvantage of this method is a connection requirement to the steel reinforcement and full rebar continuity. In this technique, a cell constant is dependent on cover depth (which varies over the surface) and the rebar diameter whose precise measurements are impossible due to lack of exact current flow prediction [7]. For cover depth, disc and bar diameters being 10-50 $\mathrm{mm}$, the cell constant is approximately $0.1 \mathrm{~m}$. Hence, the resistivity can be derived using

$$
\rho(\text { disc })=0.1 \times R(\text { disc }- \text { bar }) .
$$

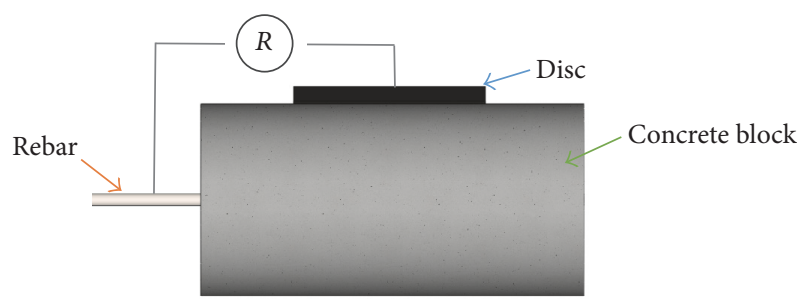

FIGURE 2: Setup of one electrode-disc: measurement of concrete resistivity (reproduced from [7]).

2.2.3. Wenner Four-Point Line Array Test. The Wenner probe technique was first introduced for the geologist's field in order to determine soil strata by Wenner at the National Bureau of Standards in the 1910s and then modified through time for concrete application [15]. In this technique, four equally spaced linear electrodes are used to measure the surface electrical resistivity of concrete (Figure 1(b)). The two exterior electrodes apply an AC current to the concrete surface while 
the electrical potential is measured from the interior probes. It should be noted that DC current is not desirable as it may result in inaccurate readings because of polarization effect. The effect of current frequencies on measurements is discussed in Section 5.2.6 (studies on electrical signal shape and frequency). The constant cell is defined as (4) for semiinfinite homogenous material [6]:

$$
k=\gamma \cdot a,
$$

where $a$ is the distance between the equally spaced electrodes and $\gamma$ is the dimensionless geometry factor which is equal to $2 \pi$ for semi-infinite concrete elements such as concrete slabs [6]. However, the geometry factor is different for tests conducted in a laboratory condition on small cylinders or cubic specimens. To measure the surface electrical resistivity, AASTHO TP 95-11 is the only specified standard which requires an electrode spacing of 1.5 inch (or $38 \mathrm{~mm}$ ) with an $\mathrm{AC}$ frequency of $13 \mathrm{~Hz}$ [3]. Due to its configuration, this method is reliable for on-site measurement; however many factors that will be discussed in Section 5 can affect the results such as rebar and cracks presence, surface conditions, concrete mixture, and environmental conditions.

2.2.4. Four-Probe Square Array Test. The four-probe square array consists of the four probes that are arranged in square position with spacing of 50 to $100 \mathrm{~mm}$ [10].

2.3. Applications. Electrical resistivity can be related to certain performance characteristics of concrete and can be used as a promising quality assurance tool for fresh or hardened concrete [6]. Some of these correlations will be discussed in the following sections. It can be used as a measure of concrete resistance to chloride ingress as well as corrosion initiation and rate measurements. The concrete diffusion coefficient as an important factor in the service life estimation of structures also can be obtained by electrical resistivity technique. In addition, it is a reliable test method to detect and monitor the initiation and propagation of cracks in concrete since they change the connectivity of concrete pore structure, and thus its electrical conductivity [16]. Cement mortars and concrete setting time can be determined through the concept of electrical resistivity. However, the correlation between setting time and concrete durability is not fully understood. Another potential application of the electrical resistivity method is to compute the moisture content of concrete, although reliability of this method is still under question [5]. However, electrical resistivity method is a simple and reliable nondestructive test method; the application and reliability of this method in determining certain characteristics of concrete has yet to be widely evaluated. This is more due to the limited knowledge in this area especially for on-site evaluation.

\section{Objective and Methodology}

The primary objective of this paper is to review the existing state of practice on the electrical resistivity measurements technique. This paper also identifies the applicability and limitation of electrical resistivity method and reviews the correlation between resistivity and certain durability properties of concrete. Correlation between surface and bulk electrical resistivity and their applications is also discussed. Finally, key parameters affecting the electrical resistivity readings are identified for future research in the area.

An extensive literature search was undertaken from most relevant publications in the area. A comparison was made of the experimental setup (Section 4), and the way in which the correlated data was obtained between resistivity and durability properties of concrete (Sections 6-8). Several parameters influencing the concrete resistivity were identified and compared (Section 5). The information observed from the literatures was based on experimental and numerical studies. The reviewed data was compiled in tables and later compared. Detailed information on the experimental setups is presented in Abbreviations section and Tables 1-4. The literature search covered both laboratory and field investigation.

\section{Comparison of the Experimental Investigations}

In this section, experimental setups developed by other researchers have been summarized in Tables 1-4. These tables consist of specimens' configuration, materials type, resistivity measurement techniques, and specimen curing/exposure conditions. The data in the tables is arranged in the order in which the citations appear in Sections 5-8. An additional row that contains authors' data on measuring electrical resistivity of simulated field circular hollow-section columns is also included. The extent to which differences in the setups can influence electrical resistivity measurements are discussed later in Sections 5-8 using data presented in this section. A comparison of the experimental setups is given in Sections 4.1-4.3. Abbreviations and symbols are defined in Abbreviations section.

4.1. Specimen Geometry and Setup. Frequently, in the electrical resistivity studies, samples with dimensions between 100 and $400 \mathrm{~mm}$ were used (Table 1). Specimens with dimensions over $1000 \mathrm{~mm}$ to simulate real-world condition were more seldom used. According to Table 2, the steel rebar diameter varied from 4 to $25 \mathrm{~mm}$. In most cases, no detailed information was provided about the type of steel embedded; both smooth and ribbed steel was used. Cover depth ranging from 10 to $80 \mathrm{~mm}$ was considered for steel reinforcement bars in the majority of the experimental investigations. For those studies investigating the relationship between steel reinforcement corrosion and concrete resistivity, chloride ingress was the major cause of corrosion. However, no information was provided on the size of the anode and the ratio between anode and cathode in the reviewed articles. Only one study concentrated solely on carbonation-induced corrosion.

4.2. Materials and Exposure Conditions. According to data in Table 1, concrete or mortar samples were casted with a w/b ratio between 0.4 and 0.65 by mass in most reviewed 


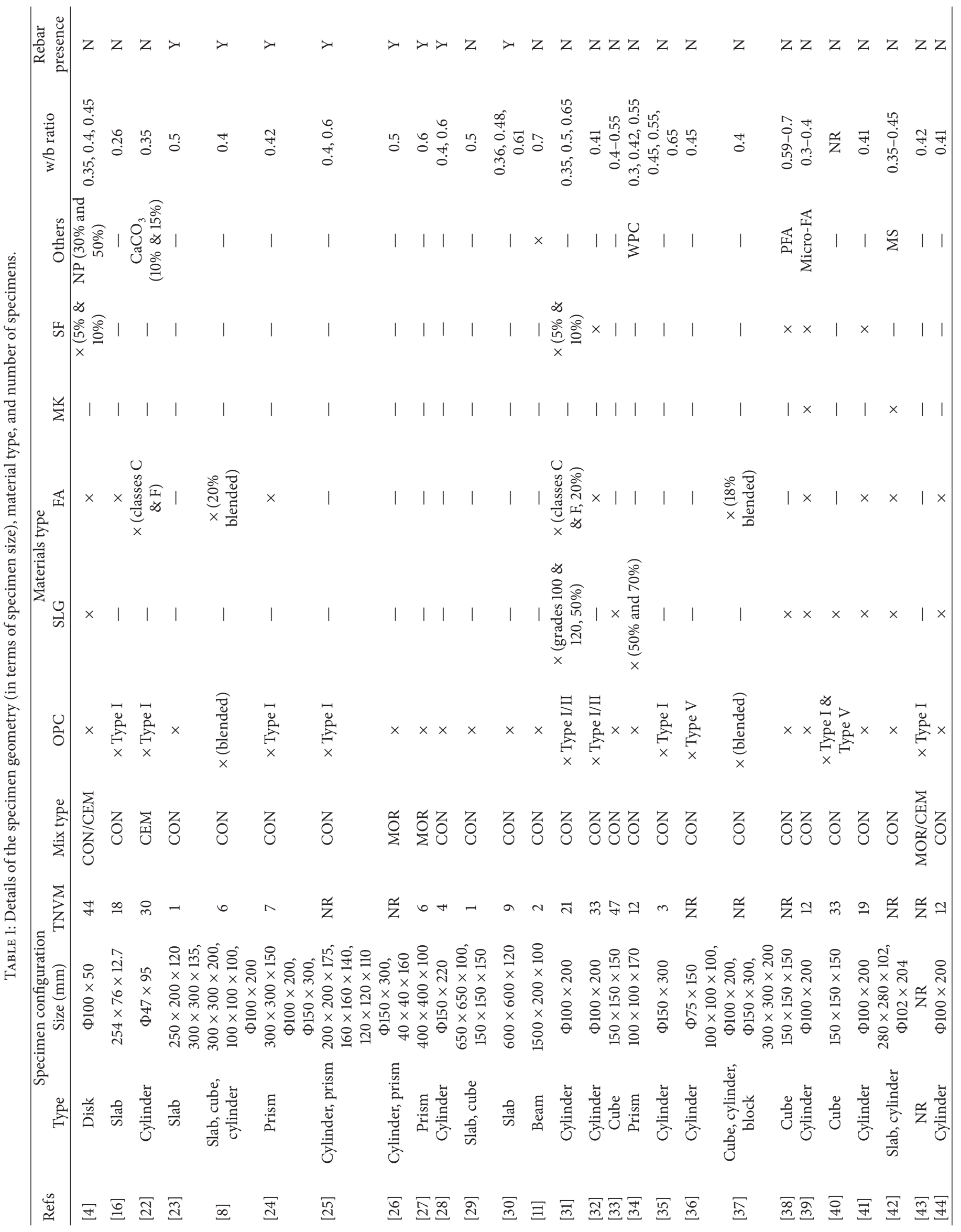




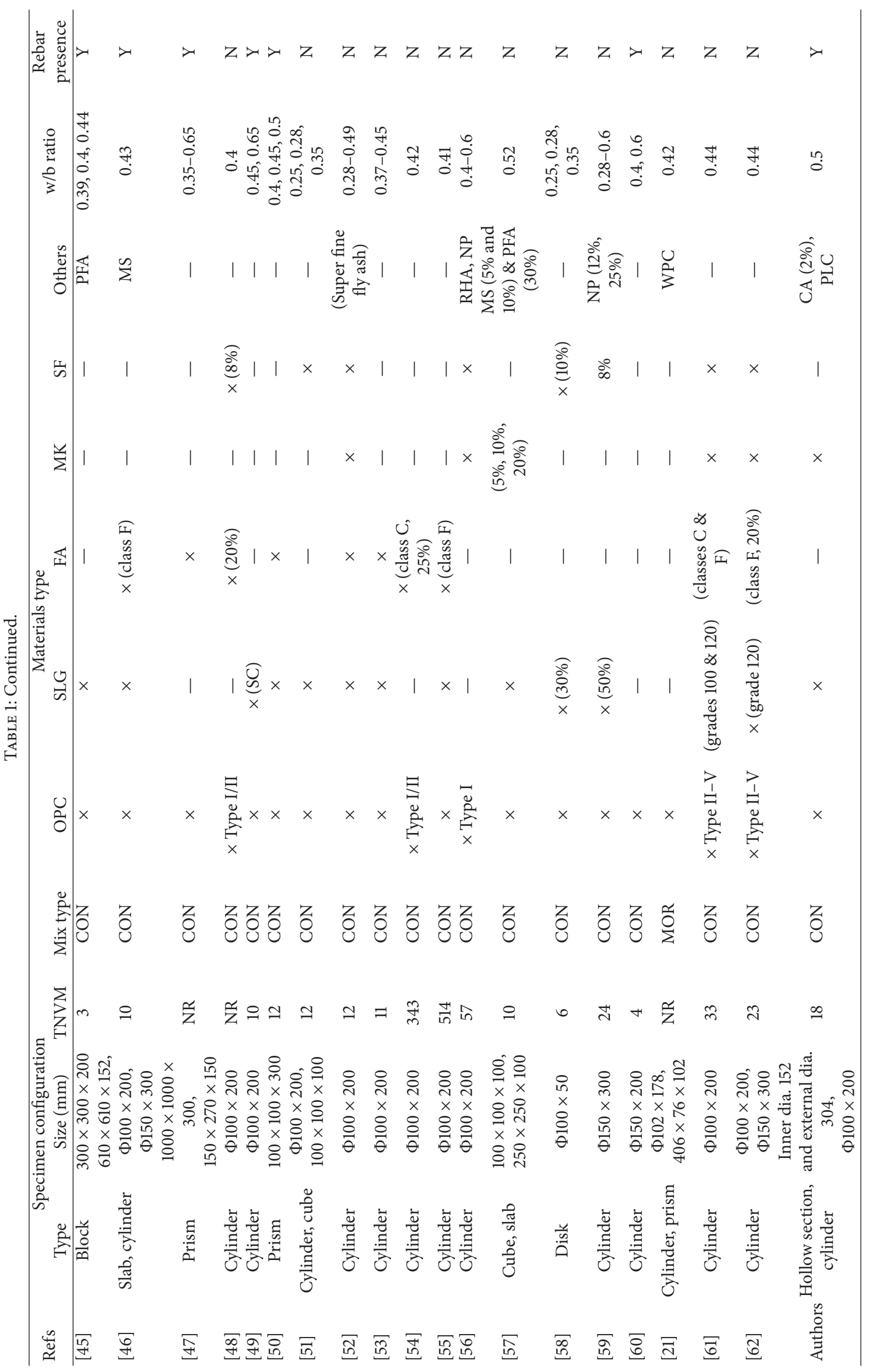


TABLE 2: Details of the reinforcements and measurement methods used to record corrosion rate.

\begin{tabular}{|c|c|c|c|c|c|c|c|}
\hline \multirow[b]{2}{*}{ Refs } & \multicolumn{3}{|c|}{ Reinforcement } & \multirow[b]{2}{*}{ Cause of corrosion } & \multicolumn{3}{|c|}{ Corrosion rate } \\
\hline & $\Phi(\mathrm{mm})$ & Length $(\mathrm{mm})$ & $\begin{array}{l}\text { Cover depth } \\
\quad(\mathrm{mm})\end{array}$ & & Technique & Details & $\begin{array}{l}\text { Correction } \\
\text { for ohmic } \\
\text { drop }\end{array}$ \\
\hline [23] & 10 & 200 & $1,10,20$ & Carbonation & - & - & - \\
\hline [8] & 10 & 300 & $50 \& 75$ & $\begin{array}{l}\text { Not studied (NS) } \\
\text { (only effect of rebar } \\
\text { presence on resistivity } \\
\text { measurement was } \\
\text { considered) }\end{array}$ & - & - & - \\
\hline$[24]$ & 16 & 300 & 50 & $\begin{array}{l}\text { Cyclic ponding with } \\
\text { sea water }\end{array}$ & - & - & - \\
\hline [25] & 4 & $110,160,200$ & $\begin{array}{l}\text { Various } \\
(53.5-100)\end{array}$ & NS & - & - & - \\
\hline [26] & 8 & 40 & 80 & NS & - & - & - \\
\hline [27] & $13,19,25$ & 410 & $20,30,40$ & NS & - & - & - \\
\hline [28] & 10 & 250 & 150 & $\begin{array}{c}\mathrm{NaCl} \text { solution/marine } \\
\text { exposure }\end{array}$ & LPR & $\begin{array}{l}\text { Embedded } \\
\text { steel rebar }\end{array}$ & $\mathrm{N}$ \\
\hline [30] & 10 & - & 25 & NS & - & - & - \\
\hline [45] & 16 & 200 & 50 & $\begin{array}{c}\mathrm{NaCl} \text { solution/marine } \\
\text { exposure }\end{array}$ & - & - & - \\
\hline$[46]$ & NR & NR & NR & $\mathrm{NaCl}$ solution & LPR & NR & NR \\
\hline$[47]$ & NR & NR & 70 & $\mathrm{NaCl}$ solution & - & - & - \\
\hline [49] & 16 & NR & 42 & $\mathrm{NaCl}$ solution & NR & $\begin{array}{l}\text { Embedded } \\
\text { steel rebar }\end{array}$ & NR \\
\hline [50] & 8 & 150 & 10 or 30 & $\mathrm{NaCl}$ solution & LPR & $\begin{array}{l}\text { Embedded } \\
\text { CE \& RE on } \\
\text { the surface }\end{array}$ & $\mathrm{N}$ \\
\hline$[60]$ & 10 & 200 & 15 & $\mathrm{NaCl}$ solution & - & - & - \\
\hline Authors & 10 & 914 & $19-38$ & $\mathrm{NaCl}$ solution & LPR & $\begin{array}{l}\text { Embedded } \\
\text { steel rebar }\end{array}$ & $\mathrm{Y}$ \\
\hline
\end{tabular}

experimental programs. The mixture proportions and cement content varied and blended cements such as fly ash or slag cements were used in parts of studies. In a couple of studies, no detailed information was provided about the cement type. However, ASTM Type I and CEM I/II cements were used in most of the articles. Only one reported study used White Portland Cement (WPC) [34]. Also, Rice Husk Ash (RHA) as a cementitious supplementary material was only studied by Gastaldini et al. [63]. Work done by authors of this paper seems to be the only one that considered crystalline admixture as a healing agent to investigate its effect on electrical resistivity of concrete.

The specimens were cured and exposed to various and/or changing conditions over the testing period (Table 3 ). In most studies, samples were cured in the lime-saturated water tank with controlled temperature to eliminate the temperature effect on resistivity measurements. The temperature was kept constant between $20^{\circ} \mathrm{C}$ and $25^{\circ} \mathrm{C}$ in most experiments. To achieve a wide range of concrete resistivity, drier climates were considered occasionally. In most experiments, specimens were kept in a water tank during resistivity measurements or exposed to a high relative humidity $(\mathrm{RH})$. For those studies focused on accelerating corrosion process,
$\mathrm{RH}$ between $90 \%$ and $95 \%$ was chosen as an exposure regime. In parts of studies, samples were exposed to outside climates, in particular marine conditions (similar to authors' experimental setup). In general, laboratory experiments were undertaken over a period between 28 and 365 days. Only a few studies measured electrical resistivity for a period over one year $[42,50,64,65]$.

4.3. Measurement Methods. Either two-electrode or fourpoint electrode (Wenner probe setup) techniques were employed to record concrete electrical resistance, which is then converted into resistivity by multiplying it with an appropriate geometrical factor. The limitations of 2-electrode method resulted in using Wenner probe configurations in most studies specially for field investigations. In experimental studies that attempted to find correlation between concrete electrical resistivity and its durability parameters, other destructive and nondestructive testing techniques from standardized measuring protocol including Rapid Chloride Permeability (RCP) test, Rapid Chloride Migration (RCM) test, Bulk Diffusion (BD) test, and Ultrasonic Pulse Velocity (UPV) were employed. Authors ongoing work also employs 
TABLE 3: Details of the curing conditions, exposure conditions, and measurement period.

\begin{tabular}{|c|c|c|c|c|}
\hline Refs & Curing conditions & Temperature $\left({ }^{\circ} \mathrm{C}\right)$ & Exposure conditions & Measurement period (days) \\
\hline$[4]$ & Lime-saturated water tank & $\begin{array}{c}20 \text { (except one type mixture } \\
\text { kept in water having } 5,20 \text {, } \\
35 \text { temperature) }\end{array}$ & $\begin{array}{c}\text { Lime-saturated water } \\
\text { tank/lab condition and } \\
\text { oven dry state (only one } \\
\text { type mixture) }\end{array}$ & $\begin{array}{l}90 \text { (except ten of the } \\
\text { mixtures tested at age of } \\
365 \text { days) }\end{array}$ \\
\hline [16] & Lime-saturated water tank & $23 \pm 1$ & Lime-saturated water tank & 28 \\
\hline [22] & $\mathrm{NR}$ & $15,26,40$ & Plastic wrapped & 1 \\
\hline [23] & NR & 20 & Laboratory (air dry) & 1000 \\
\hline [8] & Water tank & 20 & $\begin{array}{c}\text { Water tank (except two } \\
\text { slabs were kept in air after } 7 \\
\text { days) }\end{array}$ & 30 \\
\hline$[24]$ & NR & NR & Various & 120 \\
\hline [25] & Lime-saturated water tank & 23 & Various & 28 \\
\hline [26] & $\begin{array}{l}100 \% \text { relative humidity in a } \\
\text { chamber }\end{array}$ & $20 \pm 2$ & $\begin{array}{l}100 \% \text { relative humidity in a } \\
\text { chamber }\end{array}$ & 28 \\
\hline [27] & Water tank & 20 & Water tank & 45 \\
\hline [28] & NR & NR & $\begin{array}{c}\text { Seashore } \\
\text { Exposure/immersed in } \\
\text { saline solution }\end{array}$ & 1000 \\
\hline [29] & Plastic wrap & 20 & Room temperature & 90 \\
\hline$[30]$ & NR & NR & NR & 28 \\
\hline [11] & Room temperature & $25 \pm 2$ & Room temperature & 28 \\
\hline$[31]$ & Lime-saturated water tank & Laboratory & Lime-saturated water tank & 56 \\
\hline$[32]$ & NR & $10-45$ & $\begin{array}{c}\text { Room condition with } \mathrm{RH}> \\
95 \%\end{array}$ & 2,190 \\
\hline [33] & Water tank & 20 & Water tank & 181 \\
\hline$[34]$ & $\begin{array}{l}\text { Wet chamber with } \mathrm{RH}> \\
95 \%\end{array}$ & $23 \pm 2$ & $\begin{array}{l}\text { Wet chamber with } \mathrm{RH}> \\
95 \%\end{array}$ & 91 \\
\hline [35] & Water tank & $23 \pm 0.5,105 \pm 2$ & Various & 28 \\
\hline$[36]$ & Wet burlap & 20 & $\begin{array}{l}\text { Oven dried and then water } \\
\text { bath }\end{array}$ & 31 \\
\hline [37] & Water tank & $20 \& 5$ & $\begin{array}{l}\text { Water tank (after } 7 \text { days, } \\
\text { some cylinders subjected to } \\
\text { air condition) }\end{array}$ & 30 \\
\hline [38] & Water tank & $20 \pm 2$ & Water bath & 720 \\
\hline [39] & Lime-saturated water tank & $23 \pm 2$ & Lime-saturated water tank & 91 \\
\hline [40] & Water tank & NR & Water tank & 365 \\
\hline [41] & Various & $21-45$ & Various & $1,100-2,200$ \\
\hline$[42]$ & $\begin{array}{l}\text { Lime-saturated water } \\
\text { tank/wet burlap }\end{array}$ & NR & $\begin{array}{c}\text { Lime-saturated water } \\
\text { tank/wet burlap for } 3 \text { or } 7 \\
\text { days }\end{array}$ & 91 \\
\hline [43] & Lime-saturated water tank & Various $(10-45)$ & Various & 65 \\
\hline$[44]$ & Various & Various & Various & 500 \\
\hline$[45]$ & $\begin{array}{l}\text { Wrapped in damp Hessian } \\
\text { and stored under polythene } \\
\text { tentage }\end{array}$ & $15-20$ & Maine exposure & 140 \\
\hline [46] & Various & $18-32$ & Salt ponding & 90 \\
\hline$[47]$ & $\begin{array}{l}\text { Water tank and laboratory } \\
\text { air }\end{array}$ & $20 \pm 2$ & $\begin{array}{l}\text { Actual tidal zone, wet and } \\
\text { dry cycle }\end{array}$ & NR \\
\hline$[48]$ & $\begin{array}{c}\text { Five various curing regimes } \\
\text { (tap water, } \mathrm{NaCl} \text { solution, } \\
\text { rog room) }\end{array}$ & Room & Various & 1500 \\
\hline [49] & Various & $20 \pm 2 /$ uncontrolled & Various & 90 \\
\hline
\end{tabular}


TABLe 3: Continued.

\begin{tabular}{|c|c|c|c|c|}
\hline Refs & Curing conditions & Temperature $\left({ }^{\circ} \mathrm{C}\right)$ & Exposure conditions & Measurement period (days) \\
\hline$[50]$ & $\begin{array}{l}\text { Six days in fog room/three } \\
\text { weeks in room condition }\end{array}$ & 20 & $\begin{array}{l}26 \text { weekly cycles of } 24 \mathrm{~h} 3 \% \\
\mathrm{NaCl} \text { solution penetration } \\
\text { and drying for } 6 \text { days/after } \\
30 \text { weeks, various } \\
\text { conditions }\end{array}$ & 52 \\
\hline [51] & Water tank & 25 & Water tank & 90 \\
\hline$[52]$ & $\begin{array}{c}\text { Moist room with a } \\
\text { sustained 100\% humidity }\end{array}$ & 23 & $\mathrm{NaCl}$ solution & 1,092 \\
\hline$[53]$ & Lime-saturated water tank & 22 & Lime-saturated water tank & 56 \\
\hline$[54]$ & Changing exposure & $23 \pm 2$ & Changing exposure & 90 \\
\hline [55] & Lime-saturated water tank & 21 or 36 & Various & 1000 \\
\hline$[56]$ & Lime-saturated water tank & $23 \pm 2$ & Lime-saturated water tank & 28 \\
\hline$[57]$ & $\begin{array}{l}\text { Water tank for } 14 \text { days } / 14 \\
\text { days in drying cabinet at } \\
40^{\circ} \mathrm{C}\end{array}$ & $20 \pm 1 \& 40 \pm 1$ & $\begin{array}{l}\text { Salt ponding (wet \& dry } \\
\text { cycle) }\end{array}$ & 270 \\
\hline [58] & Lime-saturated water tank & 25 & Lime-saturated water tank & 90 \\
\hline [59] & Chamber with RH > 95\% & 21 & Chamber with RH > 95\% & 28 \\
\hline$[60]$ & $\begin{array}{l}\text { Laboratory environment } \\
\text { (kept in plastic bag) }\end{array}$ & $14-27,3-13$ & Seashore condition & 1,000 \\
\hline$[21]$ & Water tank & $21 \pm 3$ & Water tank & 7 \\
\hline$[61]$ & Lime-saturated water tank & NR & Lime-saturated water tank & 1 \\
\hline [62] & Lime-saturated water tank & NR & Lime-saturated water tank & 730 \\
\hline Authors & $\begin{array}{l}14 \text { days wet burlap and } 14 \\
\text { days air dry }\end{array}$ & Uncontrolled & $\begin{array}{c}\text { Natural environment and } \\
\text { simulated seashore } \\
\text { condition }\end{array}$ & 720 \\
\hline
\end{tabular}

use of both 2-electrode and 4-electrode techniques as well as UPV technique.

In summary, the experimental setup can have a significant effect on the electrical resistivity measurements. Specifically, the measurement methods and environmental conditions comprise a variety of parameters affecting the obtained data. The geometry of specimen and the general setup have a minor influence on the recorded resistivity values. To investigate electrical resistivity, the material, curing condition, and exposure condition should be carefully selected. Simulating the real-world conditions is in any case desirable since the recorded data can be used later as input in prediction models. As field survey data is rarely reported in the reviewed studies, it seems critical to identify possible deviations between laboratory investigations and field conditions. Also, authors' focus currently is to find these deviations to fill this knowledge gap by measuring concrete resistivity on both laboratory-size and field-size specimens.

\section{Influencing Parameters on Electrical Resistivity Measurements}

In the following sections, investigated parameters in published literature that influences the electrical resistivity readings have been discussed. For simplicity, they have been divided into two subgroups: (1) factors affecting the intrinsic electrical resistivity of concrete and (2) factors affecting the electrical resistivity measurements.

\subsection{Intrinsic Factors Affecting Electrical Resistivity of Concrete}

5.1.1. Effect of Water to Cement (w/c) Ratio. Generally, water to cement $(\mathrm{w} / \mathrm{c})$ ratio is one of the main factors contributing in permeability of concrete and its properties. Higher w/c ratio results in a high percentage of porosity (more voids) and leads to a lower electrical resistivity value indicating a more permeable concrete [31]. However, concrete containing supplementary cementitious materials such as slag showed an irregular behaviour for various w/c ratios [31]. For instance, an increase in $\mathrm{w} / \mathrm{c}$ ratio from 0.35 to 0.65 caused an increase in electrical resistivity values, which means a less permeable concrete. Additionally, the electrical resistivity measurements are affected by the degree of hydration as further hydration typically reduces the concrete porosity and how these pores are interconnected [32]. The results from experimental study conducted by Van Noort et al. [33] on different concrete compositions with various $\mathrm{w} / \mathrm{c}$ ratio ranges also indicated that concrete's electrical conductivity increased as $\mathrm{w} / \mathrm{c}$ ratio increased. Within a hardened concrete matrix, electrical conduction flows through the fluid contained in the pores; therefore the relative volume of interconnected pores controls the concrete's electrical resistivity. Increasing the w/c ratio (at fixed cement content) leads to a higher volume fraction of hydrated cement paste in the concrete mix and results in higher concrete electrical conductivity. Similar tendency has been observed [34] even for concrete containing White Portland Cement. When w/c ratio was reduced, conductivity 
TABLE 4: Details of the different measurement methods used in the literature.

\begin{tabular}{|c|c|c|c|c|}
\hline \multirow{3}{*}{ Refs } & \multicolumn{4}{|c|}{ Measurement technique } \\
\hline & \multicolumn{2}{|c|}{ Concrete resistivity } & \multirow{2}{*}{$\begin{array}{l}\text { Rapid chloride } \\
\text { permeability test }\end{array}$} & \multirow{2}{*}{ Others } \\
\hline & Two-electrode & Four-point method & & \\
\hline [4] & 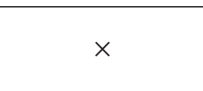 & 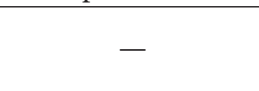 & - & $\begin{array}{l}\text { Rapid chloride migration test (NT Build } \\
\text { 492) \& ASTM C1760 }\end{array}$ \\
\hline [16] & $\times$ & - & - & - \\
\hline$[22]$ & $\times$ & - & - & - \\
\hline$[23]$ & $\times$ & $\times$ & - & Multiring electrodes \\
\hline [8] & $x$ & $x$ & - & NT Build 492 \\
\hline$[24]$ & - & $x$ & - & - \\
\hline [25] & - & $x$ & - & - \\
\hline [26] & $\times$ & $x$ & - & - \\
\hline [27] & - & $x$ & - & - \\
\hline [28] & - & $x$ & - & Steel potential \\
\hline [29] & $\times$ & $x$ & - & - \\
\hline [30] & - & $x$ & - & Ultrasonic Pulse Velocity \\
\hline [11] & - & $x$ & - & Electric imaging \\
\hline [31] & - & $x$ & $\times$ & - \\
\hline$[32]$ & - & $x$ & - & - \\
\hline [33] & $x$ & - & - & NT Build 492 \\
\hline [34] & - & $x$ & - & - \\
\hline [35] & - & $x$ & - & - \\
\hline [36] & $\times$ & - & - & - \\
\hline [37] & $x$ & $\times$ & - & NT Build 492 \\
\hline [38] & $x$ & - & - & - \\
\hline [39] & $x$ & $x$ & - & - \\
\hline$[40]$ & $x$ & $x$ & - & - \\
\hline [41] & - & $x$ & - & - \\
\hline$[42]$ & $x$ & $x$ & $\stackrel{\times}{\times}(\mathrm{ASTM}$ C1202) & - \\
\hline$[43]$ & $\times$ & $x$ & - & - \\
\hline$[44]$ & - & $x$ & - & - \\
\hline$[45]$ & $x$ & - & - & - \\
\hline$[46]$ & $x$ & $x$ & $\begin{array}{c}\times \\
(\text { AASHTO T227) }\end{array}$ & Half-cell potential \\
\hline$[47]$ & $x$ & $x$ & - & - \\
\hline$[48]$ & - & $x$ & - & - \\
\hline [49] & - & $\times$ & - & - \\
\hline$[50]$ & $x$ & - & - & Steel corrosion potential \\
\hline$[51]$ & $x$ & - & - & NT BUILD 492 \\
\hline$[52]$ & - & $x$ & - & ASTM C1556-04 \\
\hline$[53]$ & $x$ & $x$ & $\stackrel{\times}{\times}$ & - \\
\hline [54] & - & $x$ & $\times$ & KDOT Boil Testing \\
\hline$[55]$ & - & $x$ & - & $\begin{array}{c}\text { Bulk diffusion test (NT Build 443), NT } \\
\text { Build } 492\end{array}$ \\
\hline [56] & - & $\times$ & $x$ & Water Penetration Depth \\
\hline [57] & - & - & - & $\begin{array}{l}\text { Resistivity using disc method (one } \\
\text { external electrode) }\end{array}$ \\
\hline$[58]$ & $\times$ & $x$ & - & NT Build 492 \\
\hline [59] & - & $x$ & - & Natural diffusion test (90 days) \\
\hline$[60]$ & - & $x$ & - & Half-cell potential method \\
\hline
\end{tabular}


TABLE 4: Continued.

\begin{tabular}{|c|c|c|c|c|}
\hline \multirow{3}{*}{ Refs } & \multicolumn{4}{|c|}{ Measurement technique } \\
\hline & \multicolumn{2}{|c|}{ Concrete resistivity } & \multirow{2}{*}{$\begin{array}{l}\text { Rapid chloride } \\
\text { permeability test }\end{array}$} & \multirow{2}{*}{ Others } \\
\hline & Two-electrode & Four-point method & & \\
\hline [21] & $\times$ & $\times$ & - & - \\
\hline [61] & $x$ & $\times$ & - & - \\
\hline [62] & $x$ & $x$ & - & - \\
\hline Authors & $\times$ & $\times$ & $\times$ & UPV, half-cell potential, infrared camera \\
\hline
\end{tabular}

of pore solution was increased due to the greater ionic concentration of the solution. Su et al. [35] studied the effect of moisture content on concrete resistivity measurements. It was found that the electrical resistivity difference for mixes with 0.55 and $0.65 \mathrm{w} / \mathrm{c}$ ratios was not noticeable, although it became significant for specimens with a w/c ratio of 0.45 . It seems that both the capillary pore size effect and interconnectivity effect improve resistivity for saturated concrete with a higher w/c ratio. Long-term experimental study also showed the reduction in concrete resistivity with the increase of $\mathrm{w} / \mathrm{c}$ ratio until approximately 500 days. However, after 500 days, the resistivity results revealed a contrary behaviour because the concrete specimens kept in unsaturated condition (in a laboratory environment) with higher $\mathrm{w} / \mathrm{c}$ ratio favored the carbonation process that led to larger resistivity values for more advanced ages. Saleem et al. [36] also found similar trend for concrete samples contaminated with sulphate/chloride. About $15-20 \%$ reduction in electrical resistivity values was reported when the water/cement ratio increased from 0.4 to 0.6 [25].

5.1.2. Effect of Aggregate Size and Type. In general, aggregates depending on their location and size have a higher electrical resistivity compared to hardened cementitious paste because they have less porosity; thus electrical current can easily flow through the pore system of the paste. Hence, a number of researchers attempted to investigate aggregates' effect on electrical resistivity measurements. The experimental study performed by Sengul [4] indicated that increasing aggregate content resulted in higher electrical resistivity. He also observed that the resistivity of the mixture containing $60 \%$ aggregate with the size of $16-32 \mathrm{~mm}$ was approximately 3 times higher than that of the hardened cement paste [4]. Increase in aggregate content and reduction in cement paste for a given volume resulted in higher resistivity values because of replacing the porous hardened cement paste with denser aggregates. The investigation on comparing effect of two different aggregate sizes $(0-4 \mathrm{~mm}$ and $16-32 \mathrm{~mm}$ ) on electrical resistivity showed that larger aggregate size resulted in higher electrical resistivity values. Morris et al. [18] also reported that the variability was greater on the specimens with larger maximum aggregate size. Two possible causes of this variability originate from the tortuosity effect and formation of more interfacial transition zone (ITZ) (more porous structure compared to bulk cement paste) for smaller aggregate/particle size. Therefore, variation in aggregate content and size should be taken into account when comparing the resistivity values of different concretes.

As reported in the Sengul study [4], aggregate type also affected the electrical resistivity of concrete. For electrical resistivity measurements, comparison between the crushed limestone aggregate and gravel showed higher values when crushed limestone was used [4]. Gravel was rounded shaped aggregates with smooth surface whereas the limestone aggregates have rough surface texture. Therefore, using rounded aggregates such as gravel results in poor bonding between gravel and cement paste which may also be a reason behind the variations in resistivity readings. In addition, tortuosity can be higher for crushed stone aggregates due to the rough surface texture and irregular particle shape, which, in turn, may reduce the rate of electrical flow and affect resistivity [4]. Comparable standard deviation values were also observed when different aggregate type was used with the same maximum aggregate size [18]. Furthermore, using granite as coarse aggregate with fly ash also resulted in higher resistivity measurements than the mixture containing limestone aggregate type [44]. Hence, the effects of aggregate type should not be ignored during resistivity measurements.

5.1.3. Effect of Curing Conditions. The resistivity evolution of concrete is affected by the curing regimes [48]. Two key elements influence this variation in resistivity: the degree of hydration of the cementitious material and the degree of saturation of the specimen. The numerical study performed by Weiss et al. [70] attempted to simulate a mortar with a water to cement ratio of 0.42 with three curing conditions: (a) sealed during curing and testing, (b) sealed during curing and saturated during testing, and (c) saturated during curing and testing. It was concluded that the specimen that was sealed during both curing and testing had the highest resistivity whereas the sample that was sealed during curing and saturated at the time of testing had the lower most resistivity [70]. This difference can be explained by the saturation degree of the sample. The results recommend that storing a sample underwater in the lab may cause a remarkably different degree of hydration than what may occur in a field structure. The sample that was continually saturated and the sample that was sealed and saturated at the time of testing had a similar resistivity for the same degree of hydration; however, the continually saturated sample had a higher degree of hydration at the same age [70]. For specimens cured under saturated lime water, it has also been hypothesized that 
the volume of solution in which samples are stored can affect resistivity measurements due to possible pore solution concentration or dilution via leaching $[43,70]$. According to AASHTO TP 95-11 [3], for the samples cured in a limewater tank, the average resistivity value needs to be multiplied by 1.1 while this coefficient is 1 for the specimens stored in a $100 \%$ relative humidity moist room. For a given watercement ratio, it was observed that better curing procedure yielded higher electrical resistivity [49]. For both wet and dry curing conditions experimented in the study [8], the resistivity distinctly increased with increasing age. Sample storage and curing conditions are important, as they can influence the degree of hydration, the degree of saturation, and the pore structure and solution through leaching [43]. Differences in resistivity can develop as a result of sample storage conditions and wetting the specimens prior to the resistivity measurements is recommended.

\subsection{Factors Affecting the Electrical Resistivity Measurements}

5.2.1. Presence of Rebar. A number of researchers have been exploring the effect of embedded rebar presence on concrete electrical resistivity through experimental and numerical investigation. Theoretically, electrical current fluxes take pathways having the least amount of resistivity and when there is embedded rebar in concrete, the current field is distorted. However, the alternation in current field is dependent on many factors such as orientation of rebar with respect to the probe, rebar diameter and spacing, and depth at which it is located $[17,23,71]$.

Millard [71] and Gowers and Millard [17] utilized an experimental setup with steel rebar in the tanks filled with conductive medium solution and its finite element modeling in order to study the effects of concrete cover thickness as well as rebar diameter and spacing on concrete resistivity using four-point Wenner probe. According to this study, distance between the probe and embedded rebar was found to be the main influential parameter when measurements were taken on top of the bar. It was also reported that rebar diameter is not impactful in its disturbance. Moreover, it was found that measurement errors were increased by reducing rebar spacing while measurements are taken between two parallel rebars. However, it should be noted that results were obtained from measurements on the conductive solution tank and not from real concrete block. Similar study of resistivity measurements utilizing Wenner probe on concrete block with embedded steel reinforcement showed that orienting the probe perpendicular to reinforcements significantly reduced their influence on resistivity measurements [23]. It is more common in reinforced concrete structures that rebars are available in both directions and electrically linked together but, in the tested concrete block, no lateral rebars were present which then may have different effects on measured resistivity.

Practical general guidelines were developed by Polder's work [7] from summarizing literature for the RILEM TC 154 [14] technical recommendation for taking resistivity measurement on concrete. It was identified that placing all four electrodes over an embedded rebar at 10 or $20 \mathrm{~mm}$ depth can result in errors by a magnitude of two to six times that

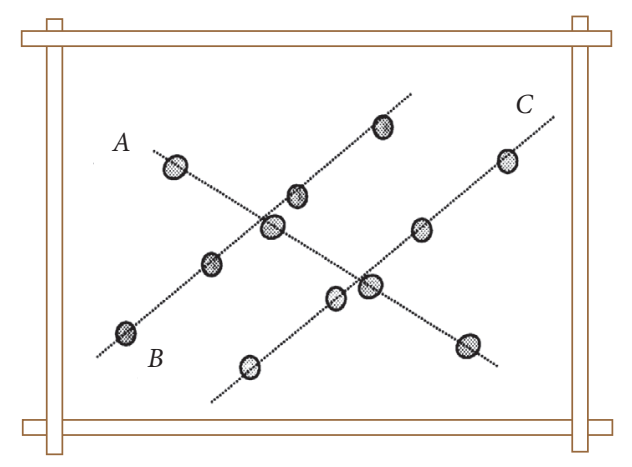

FIGURE 3: Resistivity using four electrodes at various spots in the same area to minimize influence of rebars [7].

of true resistivity and even if one of the four electrodes was near a rebar, results will lead to errors. Because of lack of research on resistivity measurements over rebar meshes, it was recommended that resistivity measurement with Wenner probe are taken in diagonal alignments on the concrete surface (Figure 3). Five measurements, each a few millimetres in distance from one another, and taking the median of them, are also suggested for collecting the resistivity value of the interested area. However, no recommendations were made for the case where it is not possible to fit all four electrodes inside the mesh unit created by the rebars. In addition, the recommended scheme in this study was not supported by any experimental and numerical works.

Another similar experimental investigation, done by Sengul and Gjorv [8], studied the effects of different parameters on concrete resistivity measurement using Wenner probe setup due to rebar presence. The study included the effective parameters: cover thickness, probe measurement directions relative to embedded rebar, electrode spacing, and probe measurement distance away from the embedded rebar. In total, five different probe positions with respect to the location of embedded steel reinforcement were considered, where four of these configurations were parallel to the rebar and the last one was perpendicular (Figure 4). Similar to Weydert and Gehlen's study [23], only a single rebar was positioned in the slab and two different thicknesses of $50 \mathrm{~mm}$ and $70 \mathrm{~mm}$ were studied. Their findings similar to the previous works stated that placing the probe orthogonally to the rebar did not influence the resistivity measurements, although significant errors were obtained once measurements were taken directly above and parallel to the rebar. It was also suggested that all measurements should be captured as far away as possible from embedded steel to reduce errors and if it is not possible due to dense reinforcement configuration, then space between electrodes should be kept relatively small. As only one rebar was placed in the tested concrete block as well as a small slab size was being used, this possibly contributed to errors due to edge effect. Hence, it may be difficult to extrapolate these conclusions to real cases.

Presuel-Moreno et al. [24, 72] have recently attempted to numerically and experimentally understand the influences of the number and configuration of embedded steel reinforcement along with the location and angle of the Wenner 


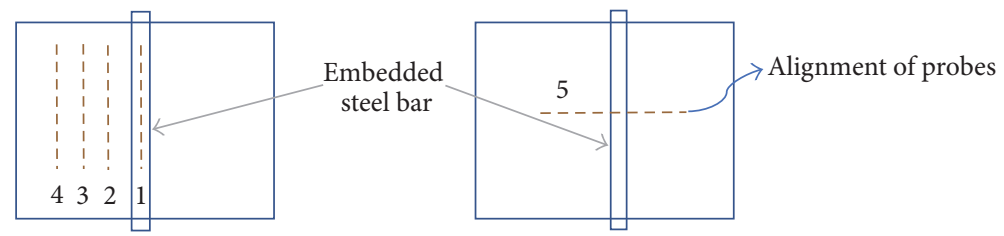

FIGURE 4: Five Wenner probe configurations with respect to embedded rebar tested by Sengul and Gjorv [8].

probe with respect to rebar alignment on concrete resistivity measurements. One of the few studies considered the effect of rebar mesh as well as orientation of the Wenner probe and demonstrated the difference between data achieved once there is a rebar mesh rather than a single rebar. Overall, six and five different orientations were investigated for the presence of a single rebar and rebar mesh, respectively. Like previous studies, it is also recommended to take the measurements perpendicular to the rebar location. However, the performance of Wenner probe due to variation in rebar spacing, cover thickness, or location and orientation of the probe with respect to the rebar mesh was not considered in this study.

Salehi et al. $[9,73]$ numerically characterized the effects of different concrete and slab thicknesses, rebar diameter, and probe arrangements with respect to the rebar mesh and rebar mesh densities on concrete electrical resistivity measurements with rebar presence using the four-point Wenner probe technique. It was concluded that the smallest error will result while setting up the probe parallel to the top rebar within the rebar mesh and perpendicular to bottommost rebar during measurements taken, as illustrated in Figure 5. It was also found that the observed resistivity decreased once the rebar mesh densities increased and the rebar diameter effect on concrete resistivity measurements can be neglected, although the numerical study results were not validated by experimental investigation.

For cylindrical concrete specimens with a single embedded steel rebar, study conducted by Chen et al. [25] suggests a correction factor to be applied to resistivity measurements corresponding to the ratio of specimen length to electrode spacing as well as the ratio of specimen diameter to electrode spacing. It was stated that no correction factor for prismatic specimens was necessary with the possibility that the applied current did not pass through the reinforcement. This research also lacked a discussion on the use of a multiple rebar and consideration of larger concrete specimens.

The effect of rebar presence on mortar electrical resistivity conducted by the four-point Wenner method was also investigated numerically and experimentally by Garzon et al. [26] and Lim et al. [27]. In Garzon et al's experimental study, small scaled cylindrical and prismatic specimens were casted. As polarization will happen due to double layer at the steel and concrete interface acting as a resistancecapacitor, resistivity measurements taken directly above rebar will result in errors. Hence, a rebar factor was suggested to be applied to the obtained resistivity results. In addition, modified Wenner equations are recommended for various geometric parameters [26]. Only reinforced cylindrical and

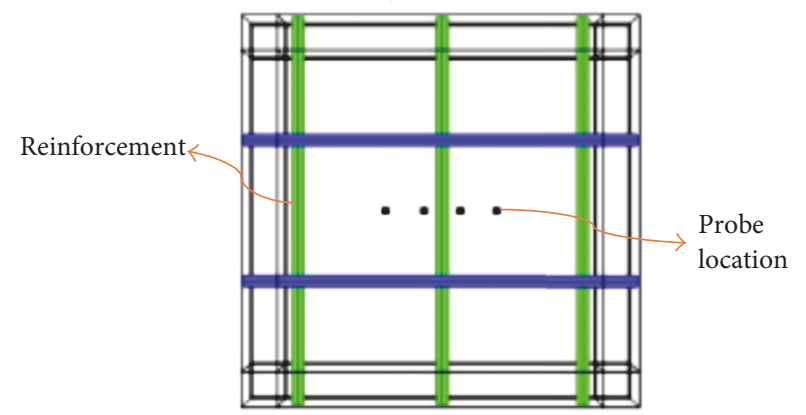

FIGURE 5: Probe configuration with respect to rebar mesh suggested to reduce electrical resistivity measurement error [9].

prismatic specimens were included in the experimental setup without considering a reinforced slab. However, in a numerical study, a slab with embedded rebar was considered [26]. The experimental investigation lacked in using concrete mixture instead of a mortar mixture which is not exactly representative of real-world cases and may lead to more errors. Furthermore, the proposed rebar factor may not be applicable to a large concrete slab with multiple rebar because their experimental conclusions are based on laboratory testing. Lim et al. [27] also studied the effects of cover depth, electrode spacing, rebar diameter, and the resistivity of concrete and reinforcement in the numerical model. However, only one probe configuration taken right above and parallel to rebar was considered. It was suggested to apply a geometric effect rate that ranges from 0 to 1 in order to estimate the reinforcement geometry impact and this rate is derived utilizing a resistivity estimation model. The geometric effect rate was also validated through the experimental investigation for on-site measurements. Based on experimental findings, it was stated that the geometric effect rate decreased with increasing concrete cover thickness and increased with increasing rebar diameter and increasing electrode spacing. Again, using mortar mixture, only one single rebar, and a single probe configuration with respect to rebar is not completely representative of real-world conditions. An error to resistivity measurements may also be introduced while the epoxy coating on the mortar specimens was used in this study due to a barrier between the electrodes and mortar surface.

The last and recent study in this category belongs to Sanchez et al. [74] who numerically proposed a modified 4-point Wenner method based on the experimental data, deployed on a bridge over the River Danube in Romania. 


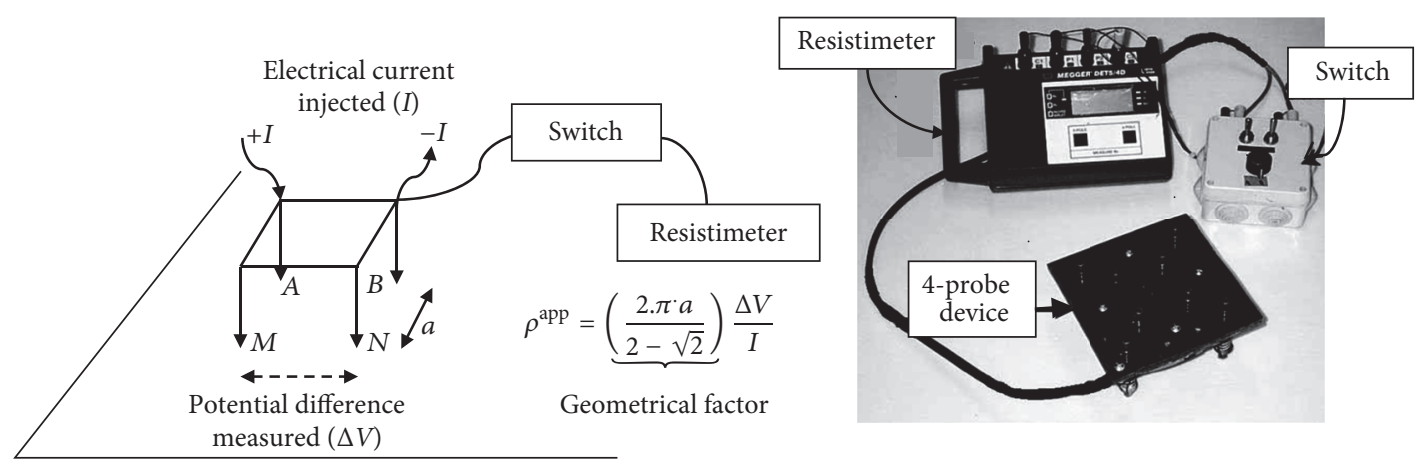

FIGURE 6: Four-probe square array principle [10].

In this study, a "rebar factor," $f_{b}$, was introduced through the modified version of Wenner method to measure the resistivity in reinforced concrete structures with thin concrete covers. Effect of rebar presence on concrete electrical resistivity measurements also can be found in detail in similar studies by $[17,28,29,65,75]$.

\subsubsection{Presence of Cracks in the Concrete Cover. Due to} the presence of cracks, apart from embedded rebar, the electrical resistivity measurements may vary using Wenner probe technique because it is initially assumed that concrete is homogeneous and isotropic with semi-infinite geometry. In this section, some researchers' investigations in order to characterize cracks in concrete conducted by electrical resistivity measurements are summarized.

Lataste et al. [10] attempt to identify and locate cracks and spalling in concrete by means of electrical resistivity. For this a utilized instrument was built to measure the electrical resistivity through the use of four electrodes in a square configuration, rather than linearly conventional Wenner probe arrangement (Figure 6). The specified built probe allows taking the measurements in two orthogonal directions without having to rotate the probe between measurements. To change the function of electrodes from current imposing to potential measurement, the use of an electrical switch was considered. Both on-site measurements on a reinforced concrete slab and laboratory measurements on a cracked reinforced concrete beam were experimentally studied. To observe the effects of crack characteristics, such as crack opening and bridging degree between crack lips and depth of crack, a numerical model was developed as well and validated experimentally. It was reported that when a conductive crack was present, depending on the direction of imposed electrical current, resistivity readings could overestimate or underestimate the true resistivity. Once current was orthogonally imposed to the crack, no impact was detected; however, reduction in electrical resistivity measurements was observed while the crack was parallel to the imposed electrical current. For an insulated crack, perpendicular readings overestimated resistivity, and parallel measurements underestimated it. It was also concluded that crack depth has a direct relation to the electrical resistivity measurements (increase in crack depth leads to increase in the resistivity measurements).
A couple of assumptions and conclusions in Lataste et al.'s work [10] may not be adaptable with reality. First, it was assumed that the rebar effect on the resistivity measurements is independent of crack depth or type which might not be true for the cases that rebar mesh or conductive crack present. Second, simulations on limited size concrete block can possibly exaggerate the crack impact. Finally, the fourelectrode square configuration, which is a less common electrode setup compared to the Wenner probe array, may generate different measurement errors.

Goueygou et al. [30] used the same square probe configuration proposed in Lataste et al's work [10] to compare electrical resistivity measurements with transmission of ultrasonic waves for characterizing, detecting, and localizing the surface cracks. For taking measurements in both directions (parallel and perpendicular), concrete beam specimens bent via three-point loading to induce one main crack were constructed. Both nondestructive techniques were capable of identifying the main simple crack inside the concrete specimens; however, complexity rose when the number of cracks increased and in most cases became impossible to detect cracks depth and patterns. Similarly, experimental and numerical investigations in detecting and characterizing cracks using electrical resistivity measurements with a square probe were done by Shah and Ribakov [76]. In their study, two experimental setups including a set of five cubic laboratory concrete specimens and a small area on a 40year-old reinforced concrete slab as well as numerical model to identify the crack depth and differentiating insulated and conductive cracks were involved. Overall, it was observed that higher resistivity values were obtained from insulative cracks while lower values resulted from conductive ones. From field data and numerical work, variations on electrical resistivity measurements were observed for different crack depth and opening [76].

Experimental study conducted by Wiwattanachang and Giao [11] also investigated the capability of concrete electrical resistivity measurements with Wenner probe method in detecting a crack development in the concrete beams. Artificial cracks made up of plastic sheet inside a concrete beam to simulate insulated cracks as well as cracks being induced in a beam by a four-step loading test on its tension face were studied in this work. After correcting resistivity 

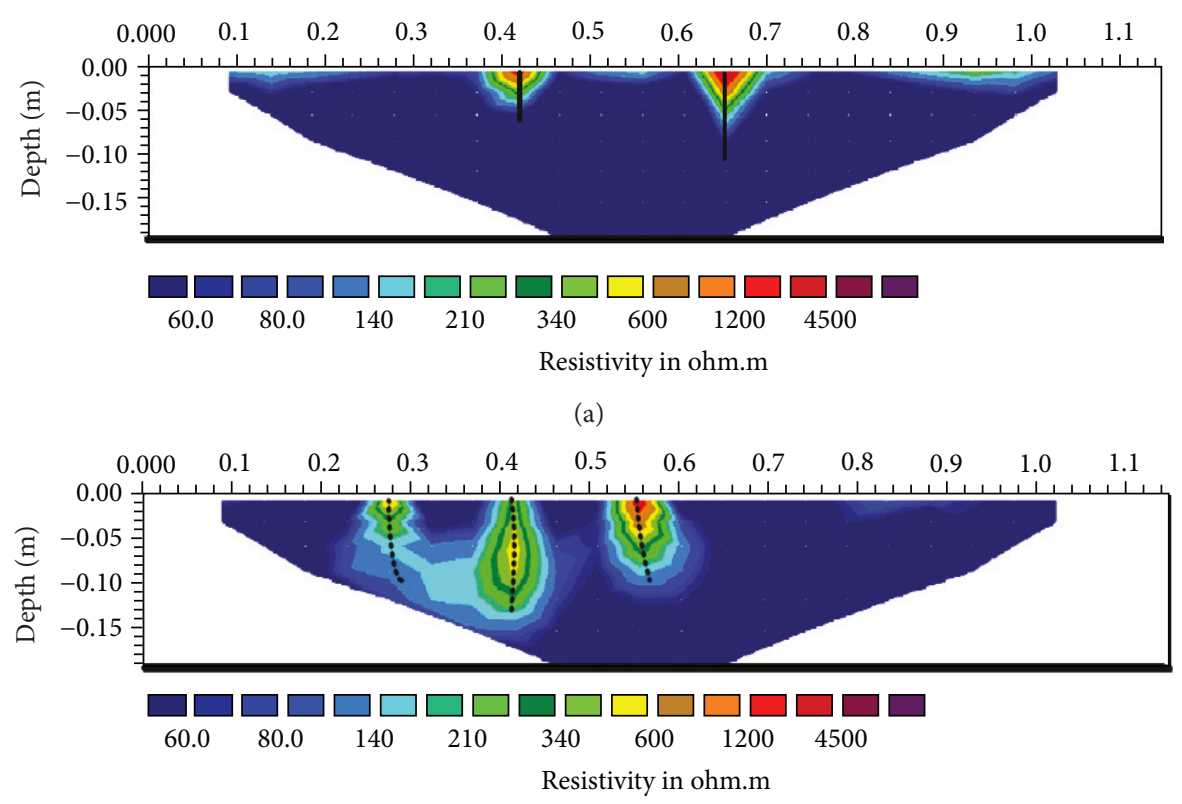

(b)

FIGURE 7: Electrical resistivity image of a concrete beam with cracks [11]: (a) concrete beam with artificial plastic sheets as crack; (b) concrete with cracks being developed from a four-point loading.

readings for the specimens' geometry, it was concluded that obtained data were increased for both crack types; although only insulated cracks were examined, conductive cracks were not. Simulated images of electrical resistivity were plotted from obtained results, as demonstrated in Figure 7. Although using electrical resistivity measurements for detecting cracks inside concrete was explored in the study, investigations on different type of cracks and their orientations toward the probe were ignored.

It was also numerically found that when cracking and delamination were present in reinforced concrete structures, electrical resistivity measurements were different from when they were not present [77]. Similar to previous studies, this finding gave rise to the conclusion that delamination at early stages can be detected using resistivity measurements with 21 linearly aligned electrodes instead of four-point Wenner method. However, proposed model in Chouteau and Beaulieu [77] only identified the effect on resistivity measurements as being different when cracking was present. In addition, to evaluate and detect cracks and discontinuities, such as joints, in massive concrete structures within preexisting boreholes, electrical resistivity measurements with a DC current was stated to be a good quality assessment indicator [78]; however, using a DC current rather than AC current may result in unfavorable results due to polarization effect which was not considered in Taillet et al. [78].

A comprehensive numerical study by Salehi et al. [79] on the effect of different cracks types, depths, and widths incorporating both the presence of cracks and rebar mesh indicated that measurements on conductive cracks result in lower electrical resistivity values. For conductive cracks, numerical results showed that decreasing crack depth did not significantly disturb the electrical resistivity measurements.
Furthermore, for an insulated crack between two inner electrodes, electrical resistivity readings led to a maximum error of about $200 \%$ higher than actual concrete resistivity. Conductive crack in here represents as a crack filled with water and insulated one denotes a crack without bridging and filled with air. It was also concluded that once the crack depth decreased, lower errors were observed. Also, the rebar and crack were found to act independently of one another while rebar mesh was present. Salehi et al.s work lacked validating numerical investigation with an experimental study. Following this study, Morales [75] experimentally investigated the effect of rebar, chloride ingress, corrosion, and various crack types on concrete electrical resistivity measurements. For all moisture conditions, it was suggested that discrete cracks of all depth and conductivity properties should be avoided in order to minimize potential errors when performing resistivity measurements. Although it was observed that electrical resistivity measurements were not significantly affected by surficial microcracking, it may be able to identify delamination as the difference observed between measured resistivity of in-tact and delaminated concrete covers. Still, investigations on the effects of cracking induced by corrosion and insulated and conductive cracks with bridging conducting electrical resistivity measurements lacked in this study.

5.2.3. Probe Spacing. Concrete is considered to be a heterogenous material and this is one of the assumptions behind the Wenner probe method. However, this assumption appears to be a likely source of error since aggregates inside concrete typically have greater resistivity and they propagated widely in different locations with various sizes. Hence, this inconsistency in the initial assumption of concrete homogeneity may 
affect resistivity measurements. To mitigate this issue, some researchers recommended considering enough wide space between electrodes (usually between $20 \mathrm{~mm}$ and $70 \mathrm{~mm}$ ) in order to reduce the influence of nonhomogeneity due to the aggregates presence $[8,18,71]$. It was suggested to take several readings at various locations and then these measurements should be averaged. Many commercial instruments are also equipped with a variable probe spacing as well to allow the device to measure concrete resistivity involving larger aggregate size.

One recommendation to help reduce variance in resistivity measurements is to consider probe spacing 1.5 times higher than the maximum aggregate size [17]. It was observed that when probe spacing became smaller than the maximum aggregate size, standard deviation in the measurements increased to around 10\% (Figure 8) [17]. For various probe spacing $(16 \mathrm{~mm}, 25 \mathrm{~mm}$, and $50 \mathrm{~mm})$, Millard [71] experimentally found that as the maximum aggregate size became closer to the probe spacing, the scattering in the observed results increased. Therefore, to compensate for the local effect of aggregates, larger electrode spacing should be considered for practical purposes. For concrete cubes $(100 \times 100 \times$ $100 \mathrm{~mm}$ ), while the electrode spacing was changed in different steps from 20 to $35 \mathrm{~mm}$, the relative resistivity measurements increased by approximately 70\% [37]. Increasing electrode spacing also resulted in increasing resistivity values to even a greater extent than that in the cubes for concrete cylinders [37]. Increase in resistivity observed due to wider spacing is in part also due to finite geometry and not just the aggregate size. The results of the resistivity measurements preformed on 28day water-cured concrete slabs with and without embedded steel rebar indicated only a small difference for probe spacing less than $30 \mathrm{~mm}$ [8]. For larger electrode spacing, however, both the steel rebar and the probe spacing showed significant impact on the electrical resistivity measurements, and the larger the electrode spacing, the larger the effect of the steel rebar. For instance, increase in electrode spacing from 20 to $70 \mathrm{~mm}$ led to increase in resistivity by approximately $26 \%$ for the slab without any steel reinforcement whereas the resistivity values either increased by $33 \%$ or decreased by $25 \%$ depending on the orientation of taken measurements (perpendicular or parallel) for the slab with rebar [8].

According to Polder [7], the electrical current may travel through the concrete volume with approximately the same depth as that of the electrode spacing. Hence, as the probe spacing increases, the current flows deeper inside the concrete volume and when the electrical current reaches the surface of the rebar, the current is transported through the reinforcement and, thus, results in lower resistivity observation [8]. For prismatic specimens, it was also suggested by Chen et al. [25] that the effects by the probe spacing can be ignored when the spacing is larger than $40 \mathrm{~mm}$; however, the resistivity values increased with less electrode spacing. For application of Wenner probe method, the important role of electrode spacing should be definitely considered during electrical resistivity measurements as it will affect the obtained results.

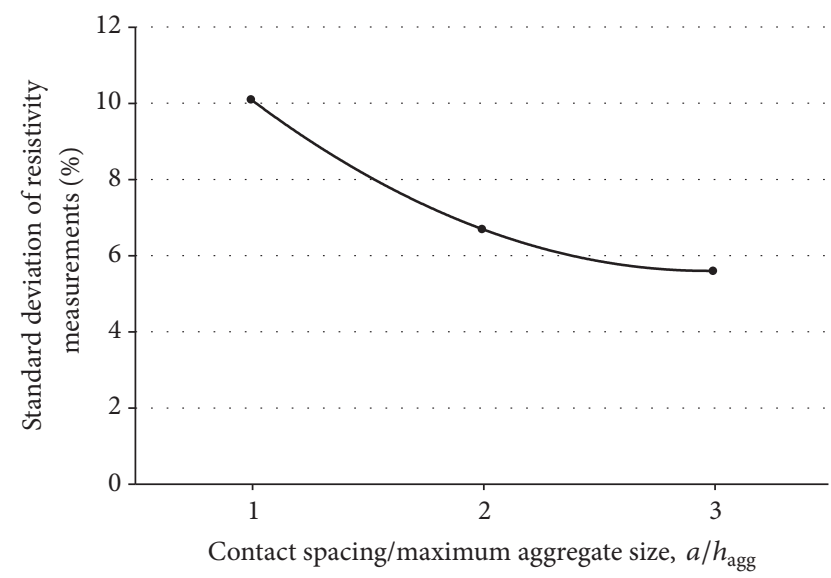

FIGURE 8: Effect of contact spacing on resistivity measurement [17].

5.2.4. Electrode Contact. The contact area between the electrodes and concrete surface may alter the electrical resistivity measurements using four-point Wenner probe. The experimental investigation in electrolytic tanks and finite element modeling resulted in the fact that the contact between the concrete surface and the probes has no significant influence on Wenner probe resistivity measurements [17, 71]. It was also reported a maximum error of $6 \%$ in resistivity (without stating lower or higher readings) when the diameter of electrode contact area varied from $1 \mathrm{~mm}$ to $40 \mathrm{~mm}$ [71]. According to Gowers and Millard work [17], misleading values can be lessened by use of a fairly low frequency and alternating current (AC). Practically, electrode contact area becomes vital for both external current imposing and internal potential measurement electrodes. It was observed by Ewins [80] that contact resistance between electrodes and concrete surface can lead to significant increase in electrical resistivity values. Both symmetry of the system and the probe performance as it was also confirmed in Gowers and Millard's work [17] may be affected by the contact resistance [80].

In two-electrode method (bulk resistivity measurements), poor contact between the plate electrode and the test cylinder surface is mainly responsible for electrode resistance. One solution to minimize the contact resistance effect is to use flexible electrodes [18]. Also, to mitigate this issue in laboratory testing, using an aid that allows for a good electrical contact such as an electrically conductive jelly was recommended $[81,82]$. Other alternative solutions included the use of soft conductive medium, saturated sponges, chamois cloth, and paper towels $[38,83]$. By using a saturated sponge, only an average of $2 \%$ difference in resistance was reported for contact resistance between the sponge and concrete surface [39]. The sponge resistance is largely dependent on the moisture content of the sponges and the conductivity of the solution in which they are saturated. It was shown that, in the twopoint measurement procedure, a sponge contacting system can give a higher resistivity than those obtained using fourpoint techniques, and careful consideration must be given to the electrode-sample contacting system when trying to evaluate concrete resistivity [40]. According to McCarter et al's work [40], the sponge contacting method introduced 
a misleading resistance originating from the sponge-sample interface that was in series with the bulk resistance of the sample. Therefore, an operator using an electrical resistivity device needs to ensure proper contact between the electrodes and concrete surface as poor contact may affect the electrical resistivity readings. The influence of electrode contact is less governing in the Wenner probe method than in the uniaxial method and, hence, measurements can be performed in a wider frequency range $(10 \mathrm{~Hz}$ to $10 \mathrm{kHz})[6]$.

5.2.5. Specimen Geometry. In the four-point Wenner method, the electrical resistivity measurements are initially presumed to be performed on the domain of semi-infinite medium which is not a practically accurate assumption. This assumption leads to deviation from the ideal condition of having infinitely large geometry which can possibly occur in different electrode orientations. For relatively small size concrete elements (e.g., cylinder or prism specimens), constriction of current to flow into a different field pattern is one of the major reasons for this deviation. Even though several researchers have realized the effect of specimens' geometry, only very limited information is available on this topic.

To account for interference between current flow and coarse aggregates in a small size sample, a suggested correction coefficient factor (or geometry correction factor) has been established in Spragg et al.'s work [84], using the simulations developed by Morris et al. [18]. The correction coefficient factor proposed formula is outlined below (see (5)) and only needs to be used when $d / a \leq 6$ or $L / a \leq 6$ (where $a$ and $d$ are parameters related to electrode spacing and specimen diameter, resp.) [84]:

$$
k=1.10-\frac{0.730}{d / a}+\frac{7.34}{(d / a)^{2}} .
$$

For a standard cylinder size $(\varphi 100 \mathrm{~mm} \times 200 \mathrm{~mm})$, the correction coefficient value ranges from 1.8 to 1.9 while using

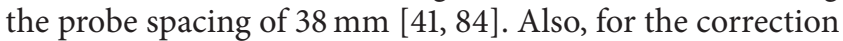
factor $(k)$, Morris et al. [18] plotted a graph based on the finite element modeling data to study a wide range of geometrical variations in concrete cylinders (Figure 9). However, this study provides wide-ranging values for correction factor; different electrode spacing and configuration as well as various geometrical concrete element types were not investigated (only $25.4 \mathrm{~mm}$ electrode spacing for concrete cylinders was considered).

According to Millard [71] and Gowers and Millard [17] through experimental findings, electrode spacing should be $1 / 4$ times smaller than concrete section dimensions and half the distance of the contact area from any element edge due to the three-dimensional current flow restriction closer to the edge. It was also observed that when the domain of the medium becomes smaller than the ideal semi-infinite condition, overestimated resistivity values resulted. Study performed by Bryant et al. [42] found an average of $24 \%$ higher electrical resistivity values for cylindrical samples in comparison with concrete slab specimens for various ages even when the geometry correction factor was used; however, Shahroodi [85] reported an average $25.8 \%$ lower resistivity

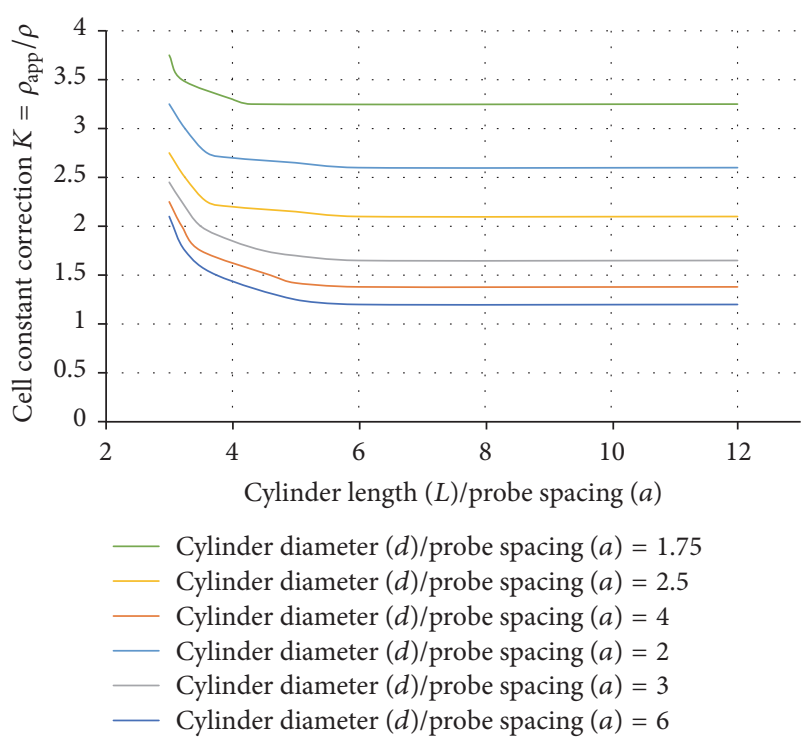

FIgURE 9: Cell constant correction to determine the concrete resistivity [18].

value. The differences in the mentioned values could possibly originate from variation in geometry correction coefficient, surface texture, device, operator, material, production, and curing process [86]. Measured resistivity values can also change by the geometry of the measuring plane. The variation in resistivity values observed experimentally by Chen et al. [25] on the curved surface and the cutting flat surface showed an increase with the volume of cutting portion. Therefore, correction factor should be applied accordingly, especially for large size specimen. They also confirmed that the resistivity of the cylindrical samples varied with the specimens' size even though the electrode spacing remains the same [25]. Furthermore, for the two-electrode method, since electrical current passes through the entire specimen volume, this measurement method is independent of specimen geometry while, for the four-point method, the depth of the electrical current passing through the concrete volume is related to both the geometry of the sample and the distance between the electrodes. This independency was also reported in Sengul and Gjorv's work [37] when the electrical resistivity values using both two- and four-electrode methods for concrete block of size $300 \mathrm{~mm} \times 300 \mathrm{~mm} \times 200 \mathrm{~mm}$ (semi-infinite geometry) and standard cylinder samples were almost the same.

5.2.6. Electrical Signal Shape and Frequency. Due to resistorcapacitor circuits' behaviour in saturated cementitious system, it introduces a phase difference between electrical current imposing and the measured potential (impedance) [43]. At different frequencies, there is a significant difference in impedance and it follows that the real component of the impedance at zero phase angle is the true uniaxial resistance. Since the phase is almost never zero, the meters record the total impedance: the real and imaginary components added in quadrature. The impedance spectrum consisting of 


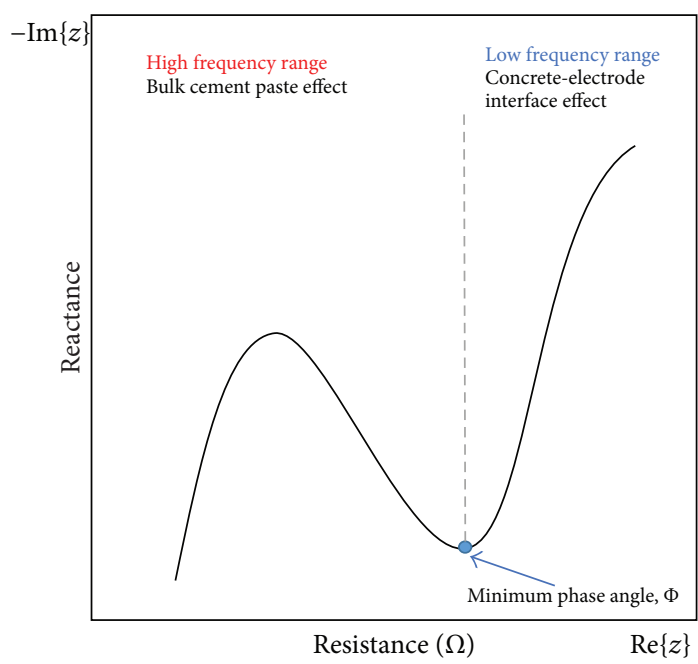

FIGURE 10: Schematic representation of the AC Impedance response of concrete [6].

two arcs in high and low frequency ranges is illustrated in Figure 10 [6]. At higher frequencies, the impedance spectrum characteristics are featured by the concrete microstructure but these characteristics are mainly attributed to the conditions at the electrode-concrete interface for low frequency domain. Generally, the frequency range in between 0.5 and $10 \mathrm{kHz}$ is used for uniaxial electrical resistivity measurements method; however, no general statement can be found on the optimum frequency since it varies with moisture contents and mixture proportions. At lower frequencies (below $500 \mathrm{~Hz}$ ), it was stated that electrical resistivity measurement can result in overestimated data because of electrode-concrete contact interface impact [6]. As it is described in Section 5.2.4, this effect is less dominant in the four-point probe method, and a wide-ranging frequency $(10 \mathrm{~Hz}$ to $10 \mathrm{kHz})$ can be conducted $[6]$.

Two signal shapes used usually for electrical resistivity measurements are sine-wave and square-wave AC current. Ewins [80] reported $800 \%$ error in results when high frequency $(600 \mathrm{~Hz})$ sinusoidal signals with poor contact were used for taking the resistivity measurements. Presence of parasitic capacitors and uneven contact resistance were the two major error sources that affected the accuracy of the measurements. However, impact from parasitic capacitors was larger. To avoid unwanted effects, using low frequency square-wave signal, instead of sine-wave, was recommended in Ewins work [80]. Similarly, it was found that sine-wave Wenner probe with $300 \mathrm{~Hz}$ frequency was adversely affected by the addition of external resistors compared to the case for which square-wave Wenner probe was used or frequency of the sine-wave signal was reduced [71]. The external resistors were used to mimic the unbalanced contact area resistance. Having unbalanced contact resistor in the voltage measurement circuit has the most significant effect on the accuracy of four-point probe method while high frequency sinusoidal AC signal is being used.
5.2.7. Effect of Temperature. Temperature variation has been reported to have a significant influence on electrical resistivity of concrete, and an increase in temperature results in a decrease in resistivity. Electrical current generally flows through the ions dissolved in the pore solution and can be affected by temperature which causes changing the ion $\left(\mathrm{Na}^{+}, \mathrm{K}^{+}, \mathrm{Ca}^{2+}, \mathrm{SO}_{4}{ }^{2-}\right.$, and $\left.\mathrm{OH}^{-}\right)$mobility and ion-ion and ion-solid interactions, as well as the ion concentration in porous media $[7,87,88]$. It was reported that the effect of temperature on bulk pore solution resistivity was noticeably different from that of cement paste or mortar with the same ion concentration, which was most likely because of strong ion-solid interactions in cement paste or mortar and less internal ionic frictions [17]. Increase in temperature has an impact on concrete isotherm curves and also tends to reduce the moisture content of concrete which indirectly affects the resistivity readings [89]. So, temperature plays an important role in concrete electrical resistivity and a number of researchers attempted to correlate its effect with true concrete resistivity values. It should be noted that not all studies performed the resistivity measurements for the different temperatures at the same moisture content. If not saturated (i.e., immersed), the concrete needs to be left for a long enough time at a given temperature and moisture. Castellote et al. [87] as well as Liu and Presuel-Moreno [41] have attempted to produce equations to convert from one temperature to a normalized temperature.

Studies conducted by Millard et al. [90] and Gowers and Millard [17] found that decrease in ambient temperature led to increase in resistivity values and suggested a correction factor of $0.33 \mathrm{~K} \Omega-\mathrm{cm} /{ }^{\circ} \mathrm{C}$ in order to compensate for the variation in temperature; however, the range of temperatures used in their studies was limited. For simplicity, a change of $3 \%$ to $5 \%$ on resistivity measurements per ${ }^{\circ} \mathrm{C}$ has been recommended for temperature range of $0^{\circ} \mathrm{C}$ to $40^{\circ} \mathrm{C}[7,67]$. A linear relationship has been developed on temperature dependency of resistivity $[45,88,91]$ :

$$
\rho=\rho_{0}(1+\alpha \cdot \Delta T)
$$

where $\rho$ is resistivity at temperature $T\left({ }^{\circ} \mathrm{C}\right), \rho_{0}$ is resistivity at reference temperature $T_{0}, \Delta T$ is temperature difference between $T$ and $T_{0}$ and $\alpha$ is temperature coefficient (between 0.022 and $0.035 /{ }^{\circ} \mathrm{C}$ ).

It was found that the above equation is only applicable over a limited interval of $\pm 5^{\circ} \mathrm{C}$ to the reference temperature [45, 88, 91]. A model developed in DuraCrete [92] also describes the correlation between $\rho_{T}$ at temperature $T\left({ }^{\circ} \mathrm{C}\right)$ and resistivity $\rho_{20}$ at $20^{\circ} \mathrm{C}$ :

$$
\rho_{T}=K_{T} \cdot \rho_{20},
$$

where $K_{T}$ is characteristic value of the temperature factor for resistivity and $K_{T}$ is defined as

$$
K_{T}=\frac{1}{1+K(T-20)},
$$

where $K=0.025$ when $T<20^{\circ} \mathrm{C}$ and $K=0.073$ when $T>$ $20^{\circ} \mathrm{C}$. 
Several researchers also defined a wide agreement for this correlation using Arrhenius law [41, 45, 87, 88, 91, 93]:

$$
\rho_{T}=\rho_{0} \cdot \exp \left[\frac{E_{a, \rho}}{R}\left(\frac{1}{T}-\frac{1}{T_{0}}\right)\right],
$$

where $\rho$ is resistivity at temperature $T(K), \rho_{0}$ is resistivity at reference temperature $T_{0}(\mathrm{~K}), R$ is gas constant $\left(8.314 \mathrm{~kJ}^{-1} \mathrm{~mol}^{-1}\right)$, and $E_{a, \rho}$ is activation energy for resistivity $(\mathrm{J} / \mathrm{mol}$ ) (ranges from $16.9 \mathrm{~J} / \mathrm{mol}$ to $42.77 \mathrm{~J} / \mathrm{mol}$ ).

The activation energy of conduction $\left(E_{a, \rho}\right)$ can be determined using the slope of a plot of the natural logarithm of resistivity and the inverse of temperature [43]. The slope of the best-fit line is multiplied by the negative of the universal gas constant $\left[8.314 \mathrm{~kJ}^{-1} \mathrm{~mol}^{-1}\right]$ to determine the activation energy of conduction. The above-mentioned correlation is published using only standard cylinder samples $(\varphi 100 \times$ $200 \mathrm{~mm}$ ) and additional work is still needed for real-world resistivity measurements and also to consider the influence generated by moisture content as an additional factor. For standard curing conditions in water at $20^{\circ} \mathrm{C}$, it was suggested that the effect of temperature can be eliminated [4]. Spragg et al. [43] stated that the resistivity measured using the same mature sample can differ by as much as $80 \%$ when the temperature of the sample fluctuates between $10^{\circ} \mathrm{C}$ and $45^{\circ} \mathrm{C}$. Additionally, several other studies showed in detail a prominent effect on resistivity results due to temperature variation $[46,47,51,52]$. In summary, when the temperature increases, electrons move faster causing higher electrical conductivity, thus lowering resistivity.

5.2.8. Effect of Moisture Content. Moisture content is one of the influencing factors that can inversely affect the concrete electrical resistivity measurements. Essentially, electrical conductivity increases with an increase in moisture content due to change in the ion mobility $[41,94]$; however, there could be a difference in resistivity between immersed samples (either water or lime water) and those in high humidity. Larsen et al. [94] found that when moisture degree decreases from $88 \%$ to $77 \%$, the resistivity increases by an average of two times and from $88 \%$ to $66 \%$ it increases by an average of 6 times. In the air-dry state, it was also reported that concrete had approximately 50\% higher resistivity than that in saturated condition [4]. As the electrical current is carried by ion flowing through the pore solution in concrete, higher moisture content leads to easier electrical flow and thus the electrical resistivity reduced. However, at low resistivity values, moisture content has less effect on the accuracy of the resistivity measurements [46]. For quality control purposes, it is essential to ensure that the same moisture degree in different mixtures and also the resistivity measurements of the specimens with low moisture content are inappropriate [25]. Furthermore, it was experimentally found that poor surface saturation using pressurized water and static ponding can lead to misinterpretation of resistivity of over $30 \%$ compared to full laboratory saturation [86]. So, additional research is still required to simulate the on-site saturation by different systems and to understand how much time is required for water to penetrate through concrete surface in order to obtain constant moisture level through the bulk specimen.

\section{Correlation between Concrete Resistivity and Its Durability Characteristics}

Through following sections, relationship between electrical resistivity and the two main concrete durability characteristics including chloride ingress and corrosion of embedded reinforcements will be presented.

6.1. Correlation between Electrical Resistivity and Chloride Diffusivity. Diffusivity is the controlling parameter which determines the time it takes for chloride ions to diffuse into concrete and reach the critical chloride threshold for corrosion initiation. Typically, this can be measured through Rapid Chloride Migration (RCM) test, Rapid Chloride Permeability Test (RCPT), or Bulk Diffusion (BD) method [95]. However, such test methods are either time-consuming or expensive for evaluating the concrete permeability properties. Hence, electrical resistivity was found experimentally and theoretically to be an efficient method that can be applied indirectly to determine concrete chloride permeability.

In theory, the relationship between diffusivity of ion species $i$ and its partial conductivity can be described by Nernst-Einstein equation [96]:

$$
D_{i}=\frac{R T \sigma_{i}}{Z_{i}^{2} F^{2} C_{i}}
$$

where $D_{i}$ is the diffusivity of ion $i\left(\mathrm{~m}^{2} / \mathrm{s}\right) ; \sigma_{i}$ is the partial conductivity of ion $i(\mathrm{~s} / \mathrm{m}) ; R$ is the gas constant $(8,314 \mathrm{~J} / \mathrm{mol})$; $T$ is absolute temperature $(\mathrm{K}) ; Z_{i}$ is the charge of ion $i ; F$ is Faraday's constant (96500 Coulombs/mole); and $C_{i}$ is the concentration of ion $i\left(\mathrm{~mol} / \mathrm{m}^{2}\right)$. By applying Archie's law, the correlation between the bulk resistivity, pore solution resistivity, and porosity can be expressed by the following $[37,97]$ :

$$
F=\frac{\rho}{\rho_{0}}=\frac{\sigma_{0}}{\sigma}=a \cdot \varphi^{-m},
$$

where $F$ is formation factor; $a$ and $m$ are constants; and $\varphi$ is porosity of concrete. $m$ is dependent on tortuosity of concrete and has been found to be 1.5 to $3.2[37,97]$. Combining the above equations gives the formation factor as a function of effective chloride diffusion coefficient of concrete $\left(D_{\text {eff }}\right)$ and chloride ion diffusion coefficient in the pore solution $\left(D_{0}\right)$ :

$$
F=\frac{D_{0}}{D_{\mathrm{eff}}} .
$$

Several researchers have also conducted various experiments to investigate the relationship between concrete resistivity and chloride diffusivity. A strong correlation between these two parameters has been reported for various concrete mixtures at different ages $[4,42,47,50-52]$. Due to presence of chloride, experimental results showed that the electrical resistivity of mortar was reduced [17]. The concrete resistivity was inversely related to chloride ingress, where lower 
TABLE 5: Classification of concrete permeability to surface resistivity values.

\begin{tabular}{|c|c|c|c|c|c|}
\hline \multirow[b]{3}{*}{$\begin{array}{l}\text { Chloride ion } \\
\text { permeability }\end{array}$} & \multicolumn{4}{|c|}{ RCP test versus surface resistivity } & \multirow[b]{3}{*}{$\begin{array}{c}\text { KDOT } \\
4 \times 8 \text { cylinder } \\
(\mathrm{k} \Omega-\mathrm{cm}) \\
a=1.5 k=1.8 \\
(\text { measured })\end{array}$} \\
\hline & \multirow[b]{2}{*}{$\begin{array}{c}\text { RCP test } \\
\text { charged passed } \\
\text { (Coulombs) }\end{array}$} & \multicolumn{3}{|c|}{ Surface Resistivity Test } & \\
\hline & & $\begin{array}{c}4 \times 8 \text { cylinder } \\
\quad(\mathrm{k} \Omega-\mathrm{cm}) \\
a=1.5 k=1.8 \\
\quad(\text { measured })\end{array}$ & $\begin{array}{c}6 \times 12 \text { cylinder } \\
\quad(\mathrm{k} \Omega-\mathrm{cm}) \\
a=1.5 k=1.8 \\
\quad(\text { measured })\end{array}$ & $\begin{array}{l}\text { Semi-infinite slab } \\
\text { (real) }\end{array}$ & \\
\hline High & $>4000$ & $<12$ & $<9.5$ & $<6.7$ & $<7.0$ \\
\hline Moderate & $2000-4000$ & $12-21$ & $9.5-16.5$ & $6.7-11.7$ & $7.0-13.0$ \\
\hline Low & $1000-2000$ & $21-37$ & $16.5-29$ & $11.7-20.6$ & $13.0-24.3$ \\
\hline Very low & $100-1000$ & $37-254$ & 29-199 & $20.6-141.1$ & $24.3-191$ \\
\hline Negligible & $<100$ & $>254$ & $>199$ & $>141.1$ & $>191$ \\
\hline
\end{tabular}

resistivity indicated the area where chloride penetration will be faster [7]; however, its effect on electrical resistivity readings is relatively small compared to carbonation process $[7,50]$. Recent field experience indicated that the relationship between surface resistivity at 28 days and 56 days with RCP data was moderate [53]. Experimental investigation by Florida Department of Transportation (FDOT) on wet cured concrete specimens in a controlled environment or cured samples in lime water, using RCP test and 4-point Wenner method in conjunction, confirmed the inverse correlation of chloride resistivity $[98,99]$. The summary of FDOT proposed relationship between resistivity and chloride can be found in Table 5. The table also shows an indication of the risk of chloride penetrability with regard to charge passed based on ASTM C1202 standard [100]. In RCP test, a $60 \mathrm{~V}$ potential is applied across the sample of $95 \mathrm{~mm}$ diameter and $50 \mathrm{~mm}$ thickness for 6 hours. Current readings are taken every 30 minutes, at minimum, and then the total charge passed in Coulombs is calculated by integrating the Current versus Time graph developed from the readings taken.

Similar experimental investigation conducted by the Louisiana Transportation Research Center (LTRC) also found a good correlation between resistivity and RCP test while the classified concrete permeability to surface resistivity values are equal to those proposed by FDOT as shown in Table 5 [31]. Following these experimental investigations, AASHTO published a provisional method TP 95-11 for indicating the concrete's ability to resist chloride ion penetration using surface resistivity measurement method [3]. However, Kansas Department of Transportation (KDOT) reported different value range for surface resistivity [54]. For instance, it is considered that chloride penetration is high when surface resistivity value is less than $7.0 \mathrm{k} \Omega-\mathrm{cm}$ for $4 \times 8$ cylinder with 1.5 -inch probe spacing which is a relatively small value compared to two other experimental results (Table 5) [54].

In addition to the experimental study on laboratory specimens, the correlation between electrical resistivity and apparent diffusivity coefficients $\left(D_{\text {app }}\right)$ is reported by researchers for field specimens $[53,55]$. Due to complexity of the exposure environments such as humidity difference, temperature, and the elevation from water level, results are scattered. However, a recent investigation on Florida bridges showed a better correlation between resistivity and apparent diffusivity once resistivity was measured under saturated condition [65]. The authors of this paper are currently involved in a study where the effect of full or partial saturation is being studied. To predict chloride threshold $\left(\mathrm{Cl}_{\mathrm{TH}}\right)$ values, the electrical resistivity method was used periodically during 1000-day monitoring of reinforced concrete element exposure to marine environment [28]. After applying the geometrical factor, the relationship between chloride content, in terms of chlorides relative to the weight of cement, and resistivity $(\rho)$ can be expressed as shown in the following [28]:

$$
\mathrm{Cl}_{\mathrm{TH}}(\%)=0.019 \rho+0.401 \text {. }
$$

A good correlation between RCM coefficients and electrical resistivity measured by two-electrode method was reported in European Union-Brite EuRam III experimental investigation [92]. Similarly, this correlation for resistivity measured by Wenner method is reported in Dhir et al's work [101]. Although resistivity measurements can be possibly a good alternative or replacement for the RCM test, more experiments need to be conducted to validate this correlation. The electrical resistivity test was suggested to be used as a quality control predictor of the chloride ingress resistance, but not as a predictor of diffusion behaviour of all kinds of concretes or as replacement of the long-term diffusion tests [56]. FDOT long-term monitoring of various concretes concluded that correlation between the RCM and the longterm tests was equal to or slightly better than those obtained by the RCP and surface resistivity due to less sensitivity of RCM test to presence of supplementary cementitious materials [102]. A linear trend exists between chloride diffusion coefficient $\left(D_{\mathrm{RCM}}\right)$ derived by RCM test and concrete electrical conductivity using two-electrode resistivity measurements [33, 46, 57, 58]. Additionally, to account for the retardation of chloride penetration due to the chloride reaction or binding with the cement phases, a factor needs to be applied to electrical resistivity measurements [59]. A reaction factor $\left(r_{\mathrm{cl}}\right)$ is defined as the ratio between the diffusion coefficients $D_{\text {app }}$ and $D_{\text {eff }}$ assuming lineal chloride binding 


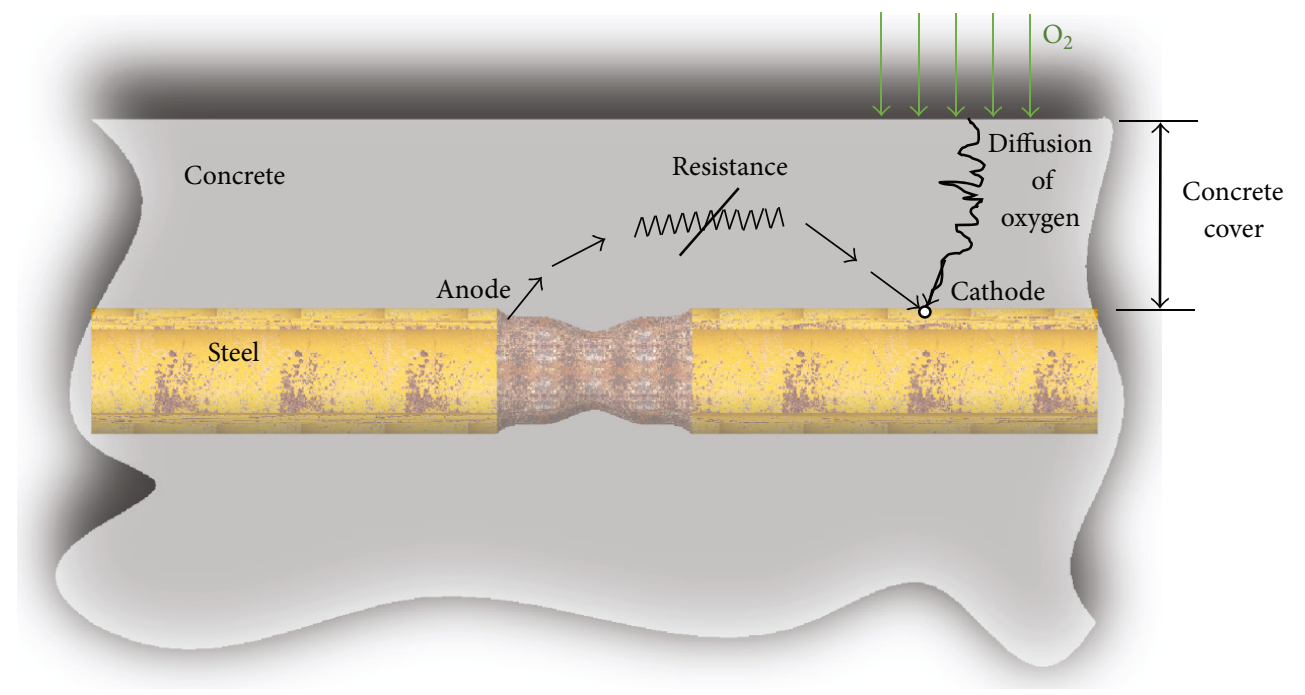

FIGURE 11: Schematic descriptions of factors which may affect corrosion rate of steel in concrete: (i) $\mathrm{O}_{2}$ availability and (ii) electrical resistance of concrete (reproduced from [19]).

as shown in (14) where $\rho_{\text {app }}$ and $\rho_{\text {eff }}$ are apparent and effective electrical resistivity [59]:

$$
r_{\mathrm{cl}}=\frac{D_{\mathrm{eff}}}{D_{\mathrm{app}} \cdot \varphi}=\frac{\rho_{\mathrm{app}}}{\rho_{\mathrm{eff}}} .
$$

\subsection{Correlation between Electrical Resistivity and Reinforce-} ment Corrosion. Once rebar is depassivated and corrosion is initiated by chloride ions or carbonation, corrosion rate will be the most influential parameter that determines how fast the reinforced concrete structure is deteriorating. It is dependent on many parameters including oxygen availability, ratio of anodic/cathodic area, relative humidity $(\mathrm{RH})$, and concrete electrical resistivity (Figure 11) [19]. When enough oxygen is available to supply the anodic current especially under aerated state (such as the splashing area zone), cathodic control no longer exists. In this condition, the corrosion rate can be limited by controlling the flow of ionic current through concrete which is directly related to electrical resistivity of concrete [19]. Therefore, several researchers have attempted to correlate the corrosion probability and corrosion rate to concrete electrical resistivity [60, 103-108].

Among all the studies conducted so far, there is an agreement that corrosive environment in reinforced concrete and electrical resistivity of concrete have an inverse relationship. As the electrical resistivity of concrete decreases, the rate of steel reinforcement corrosion increases. A theory by Glass et al. [103] stated that the corrosion rate of reinforced concrete is under anodic control with the anodic reaction being limited by the mortar resistivity. Glass's anodic resistance theory is also supported by studies conducted by Morris et al. [60] and Bertolini and Polder [104]. In their investigations, it has been found that concrete resistivity affected not only corrosion rate, but also the corrosion potential $[60,104]$. The only standardized test method for corrosion monitoring is the ASTM C876 half-cell potential mapping technique [105]. Hence, electrical resistivity measurements can be an effective standard indicator of steel reinforcement corrosion potential and rate.

Combining both half-cell potential and electrical resistivity measurements techniques makes it possible to examine corrosion probability and corrosion rate once it is initiated [106]. For high resistivity values, Carino [106] stated that even if the embedded rebar in concrete is actively corroding, detected by half-cell potential technique, the corrosion rate may be slow when steel rebar depassivates; thus the concrete electrical resistivity has better correlation with corrosion rate than half-cell potential. Experimental investigation on reinforced concrete specimens immersed in saline solution came to the conclusion that steel rebar is likely to reach a corrosion state while resistivity readings are lower than $10 \mathrm{k} \Omega \cdot \mathrm{cm}$ and reach a passive state when resistivity measurements are higher than $30 \mathrm{k} \Omega \cdot \mathrm{cm}[60]$. The results also showed that the risk for chloride-induced corrosion and the chloride threshold value that will initiate the corrosion process can be estimated via a straightforward and nondestructive technique like concrete resistivity [28]. For various concrete mixture types, Polder and Peelen [50] indicated the corrosion initiation with respect to electrical resistivity under simulated deicing salt, but no relationship or effect was established. Similarly, Basheer et al. [57] and Smith et al. [46] used both electrical resistivity measurements and half-cell potential to evaluate the probability of corrosion in embedded steel rebar but, then again, no correlation was developed. It was also confirmed that corrosion potential can be detected by means of electrical resistivity but it was not specifically indicated how this can be done [107]. In addition, using the electrical resistivity or half-cell potential measurements was suggested to evaluate the deterioration caused by corrosion in the experimental study preformed on a concrete bridge deck [108]. In this study, it was stated that having no need of electrical connection to embedded rebar is the main advantage of electrical resistivity over half-cell potential technique. The effect of concrete cover as an influential parameter on 


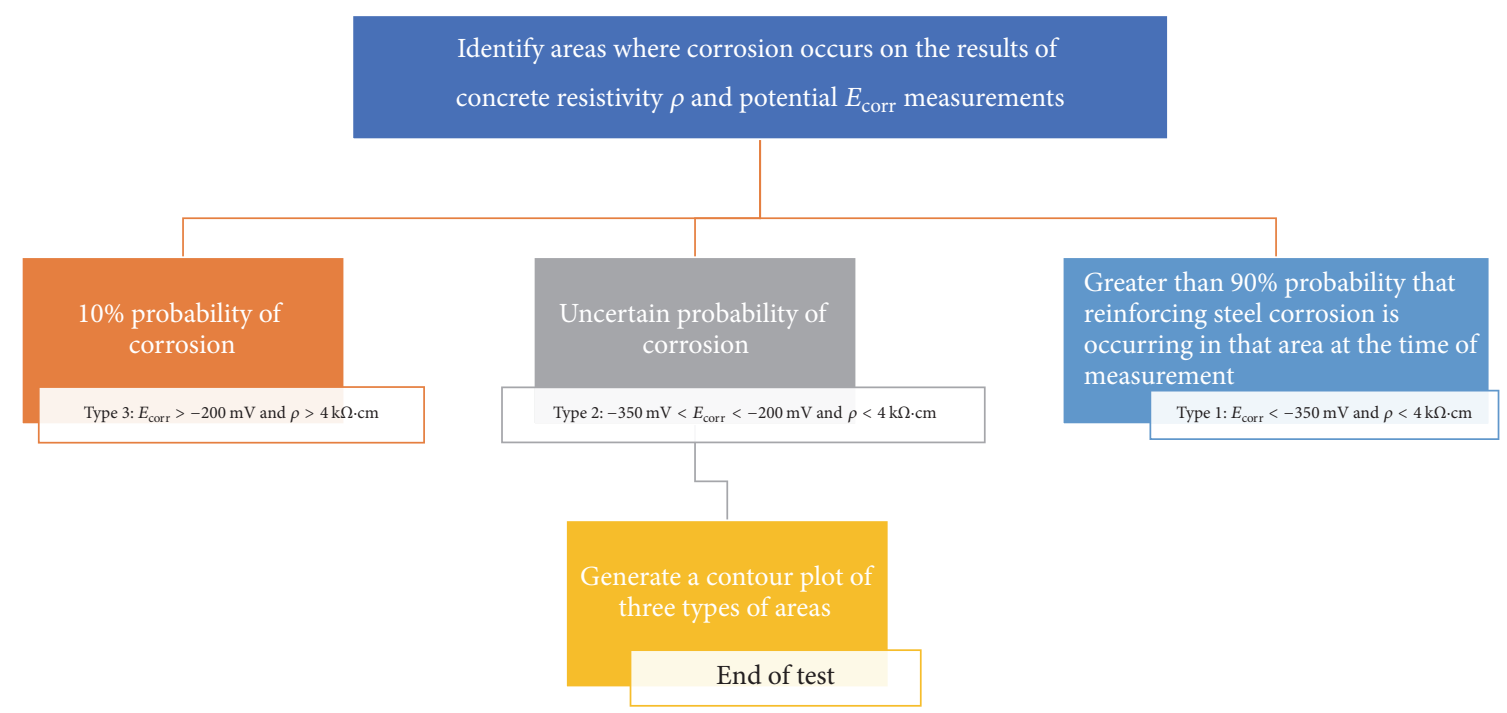

FIGURE 12: Assessment of corrosion probability in concrete slabs through half-cell potential and resistivity measurements [20].

TABLE 6: Concrete resistivity and risk of corrosion of steel reinforcement.

\begin{tabular}{|c|c|c|c|}
\hline \multirow[b]{2}{*}{ Corrosion risk } & \multicolumn{2}{|c|}{ Resistivity values $(\mathrm{k} \Omega \cdot \mathrm{cm})$} & \multirow{2}{*}{$\begin{array}{c}\text { Commercial } \\
\text { Wenner probe } \\
\text { instrument } \\
\text { manuals }[68,69]\end{array}$} \\
\hline & Polder [7] & $\begin{array}{c}\text { Song and } \\
\text { Saraswathy [66], } \\
\text { Elkey and Sellevold } \\
{[67]}\end{array}$ & \\
\hline High & $<10$ & $<5$ & $\leq 10$ \\
\hline Moderate & $10-50$ & $5-10$ & $10-50$ \\
\hline Low & $50-100$ & $10-20$ & $50-100$ \\
\hline Negligible & $>100$ & $>20$ & $\geq 100$ \\
\hline
\end{tabular}

corrosion detection using both electrical resistivity and halfcell potential measurements has been studied experimentally [75]. For small concrete cover thickness, it was observed that both measurements corresponded well together, but more discrepancy in measurements values was obtained when concrete cover became thicker [75]. From few published papers in this area that examined the possibility of corrosion by applying both electrical resistivity and half-cell potential technique, it was difficult to find a systematic methodology. As a rule of thumb, methodology proposed in Figure 12 by Sadowski [20] can be used when possible corrosion areas are identified by both half-cell potential and a four-point Wenner probe. Only identifying the probability of corrosion was suggested when conducting a corrosion assessment [20].

A number of researchers as well as commercial Wenner probe instrument manuals (Proceq and Giatec Scientific Inc. $[68,69])$ provided a general guideline in terms of corrosion risk when interpreting electrical resistivity measurements, as seen in Table 6 . The difference between provided resistivity values originates in the various experimental setup, concrete quality, concrete composition, and initial chloride concentration. For example, the corrosion state resistivity for passivation value reported in Polder's [7] review is higher than the one recorded in Morris et al's work [60] due to different experimental setup and test conditions.

A linear relationship between concrete electrical conductivity and corrosion rate has been found in several articles [104, 106, 109-111]. Experimental study on carbonated mortars also confirmed this linear trend and showed a different slope in case of chloride presence as the corrosion rate was affected by $\mathrm{Cl}^{-} / \mathrm{OH}^{-}$ratio [110]. Variation in concrete cover depth as well as concrete composition also showed an effect on the slope of linear trend between resistivity and corrosion rate [104]. Andrade and Alonso [112] proposed an empirical equation describing relationship between resistivity and corrosion rate:

$$
I_{\text {corr }} \cong \frac{3 \times 10^{3}}{\rho} .
$$

Two other similar models have been proposed by DuraCrete R17 [92] and LIFECON [113], as illustrated below:

$$
I_{\text {corr }}=\frac{k_{0}}{\rho(t)} \times F_{\mathrm{cl}} \times F_{\mathrm{Galv}} \times F_{\mathrm{O}_{2}},
$$

where $I_{\text {corr }}$ is corrosion rate in $\mu A / \mathrm{cm}^{2}, k_{0}$ is constant regression parameter in $\mu \mathrm{m} \cdot \Omega \mathrm{m} / a, \rho(t)$ is actual resistivity at time $t$ in $\Omega \mathrm{m}, F_{\mathrm{cl}}$ accounts for the influence of the chloride content, $F_{\mathrm{Galv}}$ is influence of galvanic effect, and $F_{\mathrm{O}_{2}}$ is availability of oxygen.

In most cases, $F_{\mathrm{cl}}$ is dependent on the chloride concentration at the location that corrosion occurs and $F_{\mathrm{Galv}}$ and $F_{\mathrm{O}_{2}}$ equal 1. Due to microcell geometric arrangements of anodic and cathodic sites, concrete electrical resistivity plays an important role in controlling corrosion rates [111]. Similar to Glass et al.s study [103], it was stated by Gulikers [111] that overall corrosion cell resistance is not inherently controlled by concrete electrical resistivity, but rather cathodic activation controls mostly. It should always be considered that the interpretation of electrical resistivity measurements is 


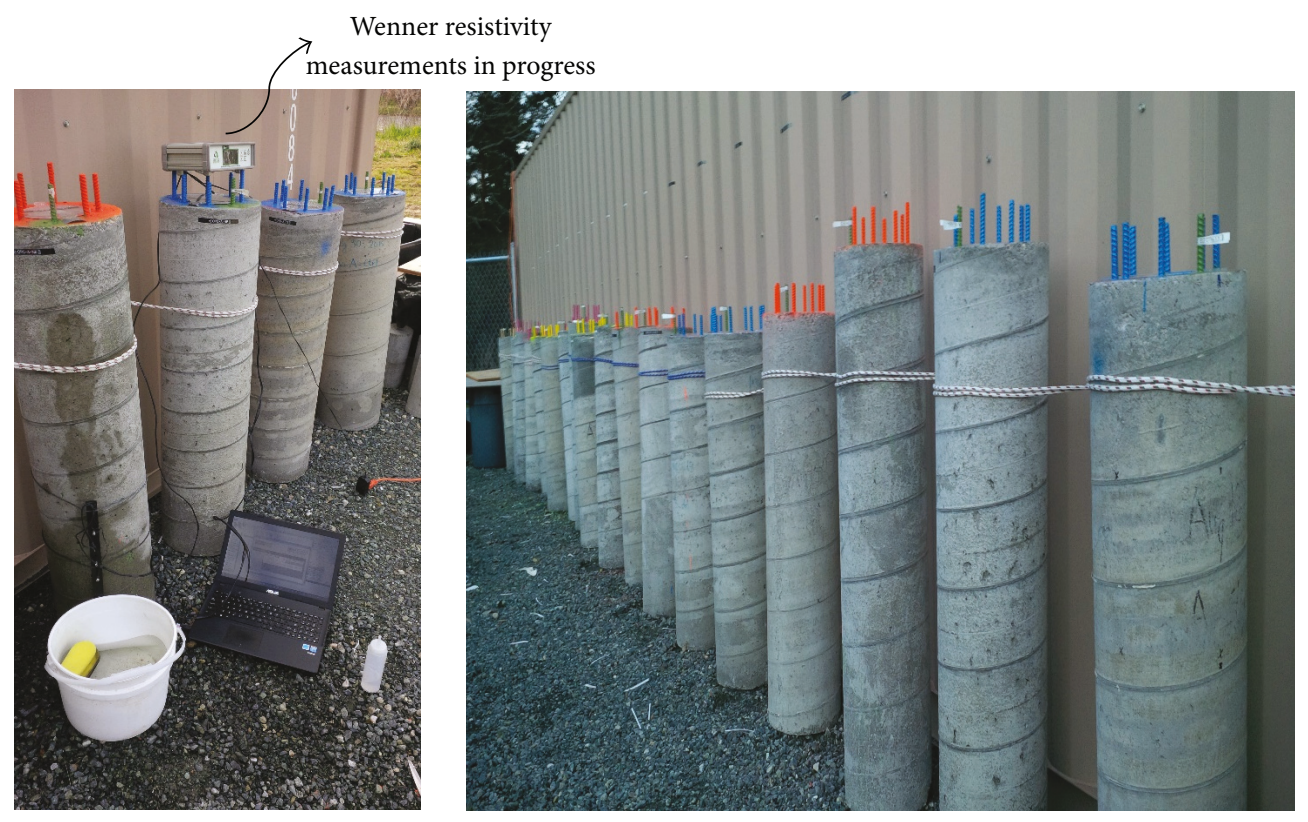

FIGURE 13: Instrumented circular hollow columns being studied by authors to establish the relationship between electrical resistivity and durability characteristics.

a challenging task due to many variables affecting the results like moisture condition, salt content, and so forth.

In summary, it can be concluded that still large range and scatter exist for correlation between corrosion rate and concrete resistivity. Also, effect of moisture state and temperature as well as corrections to corrosion rate measurements should be considered during an investigation on finding correlation between resistivity and corrosion rate. Knowledge is still lacking in the literature to understand which mechanism dominates the corrosion process and how resistivity measurements are impacted. To practically determine the corrosion and resistivity relationship, more field data should be collected and analyzed. In order to address some of these issues, authors of this paper initiated a project with field specimens as shown in Figure 13. In this study, influence of various parameters (noted below) on resistivity is being studied (parameters: cover thickness, crystalline water-proofing admixtures effect, and cement type). In addition, authors are also studying the effect of selfsealing on resistivity of concrete. Previous work done in this area (self-sealing) is reported elsewhere $[114,115]$.

\section{Correlation between Electrical Resistivity and Compressive Strength}

One of the most important mechanical properties of concrete is compressive strength. It can be simply measured by compression testing machine, as load at the failure divided by area of specimen gives the compressive strength of concrete [56]. Thus, a number of researchers performed different experiments to understand the relation between compressive strength and electrical responses in cementitious materials. In the compressive strength, one of the key factors is the strength of interfacial transition zone (ITZ) that has no remarkable impact on concrete electrical resistivity. It was observed when different cementitious materials were used in concrete mixture that there was no sensible relationship between concrete resistivity and compressive strength $\left(R^{2}=0.413\right)$ [56]. This is mainly linked to the fact that chemical compound of pore solution does not have a great impact on compressive strength while affecting the concrete resistivity significantly. On the other hand, for the case of similar cementitious materials, better correlations can be achieved between compressive strength and concrete resistivity due to relationship between permeability and compressive strength [56]. As the strength increases, the electrical resistivity increases correspondingly for the same concrete mixture design. The study on the electrical properties of concrete with White Portland Cement also found an approximately linear trend between these two properties as both directly depend on the porosity of the matrix at early age. As concrete matured, this relationship was affected by other properties such as the conductivity of the pore solution and the degree of concrete saturation [34]. Also, as the density and compactness of the concrete structure increase, its compressive strength and the electrical resistivity will both increase. It was reported that, at the same w/c ratio, the changes of the specimens' resistivities with different sizes $(\varphi 100 \mathrm{~mm} \times 200 \mathrm{~mm}$ and $\varphi 150 \mathrm{~mm} \times 300 \mathrm{~mm})$ were close to those changes of the compressive strengths. For example, the differences between the resistivities or compressive strengths of the specimens were both around $93 \%$ at w/c of 0.6 and $95 \%$ at w/c of 0.4 [25]. No direct relationship between 56day concrete electrical resistivity and 28-day compressive strength was found in Gudimettla and Crawford's work [53] due to variety of samples taken from different field projects. In terms of activation energy, the investigation done 
by Liu and Presuel-Moreno [44] showed that resistivity is noticeably higher than the reported activation energy for compressive strength. In conclusion, there is no practical correlation between electrical resistivity and compressive strength for various cementitious materials; however, for the same mixture design, electrical resistivity is linearly related to compressive strength. Generally, as concrete permeability decreases, both electrical resistivity and compressive strength increase.

\section{Correlation between Surface and Bulk Electrical Resistivity}

As it is discussed in previous sections, every electrical resistivity $(\rho)$ measurement is composed of a resistance $(R)$ and a geometry correction factor $(k)$ that convert the resistance to resistivity which is a geometry independent intrinsic material property [21]. The correction factor $(k)$ depends on the geometry and size of the sample and the electrodes location. Hence, for the same concrete material, variation in electrode geometries and sample size may result in different resistance values but eventually will yield the same resistivity using (17). Four common measurement electrode geometries that have been employed in several studies to conduct electrical test on cementitious cylinders are included: (1) uniaxial resistance (or bulk resistance), (2) surface resistance, (3) embedded sensors, and (4) disc method (one external electrode). In this section, researchers' review on correlation between the first two common (bulk and surface) resistivity measurement methods is summarized.

$$
\rho=R \cdot k
$$

Theoretically, the ratio of surface and bulk resistance for standard size cylinder specimen $(100 \mathrm{~mm} \times 200 \mathrm{~mm})$ and probe spacing of $a=50 \mathrm{~mm}$ can be computed in the following equation [18]:

$$
\frac{R_{1}}{R_{2}}=\left(\frac{\rho_{1}}{\rho_{2}}\right)\left(\frac{1}{8}\right),
$$

where $R_{1}$ is resistance measured by 4-point Wenner method (surface resistance), $R_{2}$ is resistance measured by uniaxial method (bulk resistance), $\rho_{1}$ is resistivity measured by $4-$ point Wenner method (surface resistivity), and $\rho_{2}$ is resistivity measured by uniaxial method (bulk resistivity).

The ratio of two different resistivity types $\left(\rho_{1}\right.$ and $\left.\rho_{2}\right)$ is equal to 2.63 [18]. Therefore, the theoretical ratio of surface and bulk resistance can be computed as

$$
\frac{R_{1}}{R_{2}}=\frac{2.63}{8}=0.33 \text {. }
$$

Also, a number of researchers experimentally attempted to study this correlation between bulk and surface resistivity data. Studies performed by Ghosh and Tran [61, 62] showed the correlation between bulk and surface resistivity for different groups of binary and ternary mixtures. It was observed that for most groups of mixtures, the coefficient of determination $\left(R^{2}\right)$ values for linear trend line was higher than 0.8 and sometimes close to 1 except some silica fume mixtures at early-ages where the coefficient became less than 0.80 . The linear trend line varied from 0.29 to 0.47 at different concrete ages of 7, 14, 28, 56, 91, and 161 days. For probe spacing $a=38.1 \mathrm{~mm}$, Spragg et al. [39] also reported a strong linear correlation with an $R^{2}=0.9986$, with surface resistivity measurements tending to be 1.86 times higher than bulk resistivity which supports previous work done by Morris et al. [18]. Several Department of Transportation (DOT) and other agencies participated in a round robin program (summarized by Indiana DOT). A recent study on specimens casted during actual concrete production in the field through different US states proved that the surface and bulk measurements correlate extremely well with each other at 28 - and 56-day age [53]. It was observed that the surface resistivity results were typically 1.9 times higher than the bulk resistivity obtained data. Authors have found a similar correlation between bulk and surface resistivity $\left(R^{2}=0.979\right)$.

Both surface and bulk resistivity measurement methods have been used to determine the presence of a heterogeneity problem [21]. To investigate the heterogeneous systems, the surface and uniaxial resistivity tests were performed on the cylindrical specimen with a $10-\mathrm{mm}$ thick white cement paste on outer layer and the prismatic specimens with two separate layers of white and grey cement pastes setup in parallel and series configurations, as illustrated in Figure 14 [21]. For the uniaxial case, the total resistivity $\left(\rho_{c}\right)$ can be calculated through the proposed equations (20a) and (20b) for parallel and series configurations. A correction factor $(\Gamma)$ has been developed for heterogeneity which depends on the material of interest and an approach was proposed to compare the resistivities measured from a surface test and a bulk test. In this approach, if there is heterogeneity, the values from the two tests will be different. This difference can give an indication as to whether the surface layer is more or less resistive [21]. Similarly, correlation between surface and bulk resistivity found in other studies indicated a strong relationship between the resistivity values when the appropriate geometry factor was applied $[8,37]$ :

$$
\begin{gathered}
\frac{1}{\rho_{c}}=\sum_{i=1}^{n} \frac{A_{i}}{\rho_{i}} \quad \text { (Parallel configuration) } \\
\rho_{c}=\sum_{i=1}^{n} \rho_{i} \cdot L_{i} \quad \text { (Series configuration). }
\end{gathered}
$$

In summary, the coefficient of determination value $\left(R^{2}\right)$ for linear trend between bulk and surface resistivity in different literatures for various ages is shown in Table 7 . Based on the reported data, it can be concluded that a strong relationship exists between resistivity measured by surface and bulk tests. However, in practical cases, caution is needed for multilayered cementitious composite systems as electrical current flows differently in these two techniques and for the types of layered electrical properties that can occur due to moisture gradients, chemical changes, and ionic gradients [21]. More complicated situations for resistivity measurement that arise during field measurements where seasonal and wet/drying might take place at the tidal section on partially 


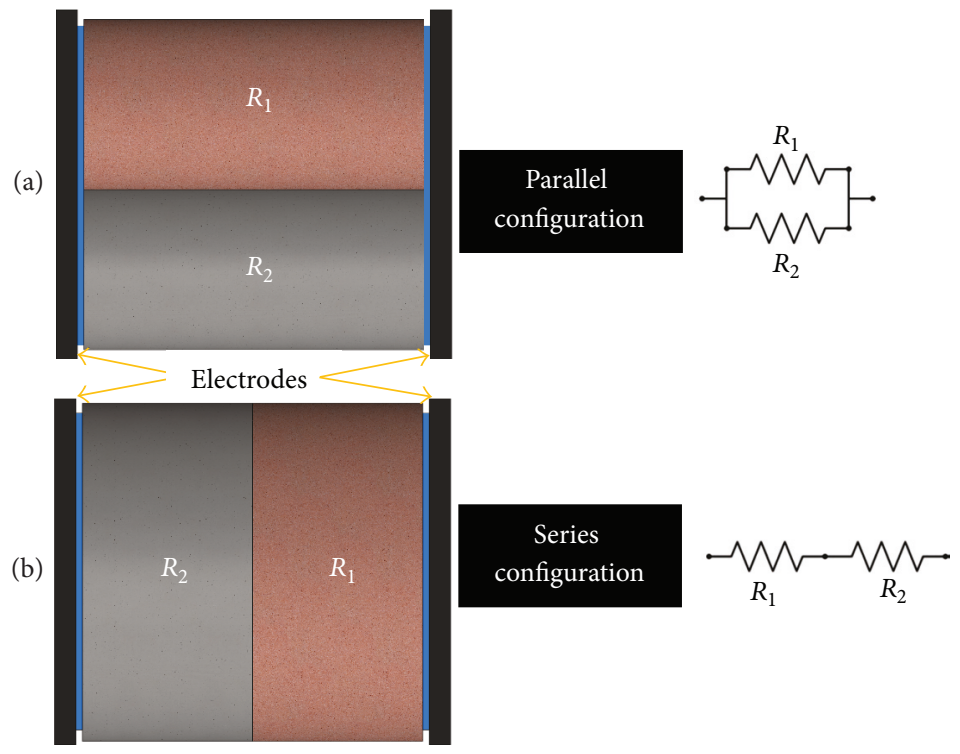

FIGURE 14: Schematic of the (a) parallel and (b) series models of heterogeneous systems (reproduced from [21]).

TABLE 7: Coefficient of determination (COD) value for linear trend between bulk and surface resistivity in the literatures.

\begin{tabular}{lc}
\hline Reference & $\begin{array}{c}\text { Coefficient of determination } \\
\text { value }\left(R^{2}\right)\end{array}$ \\
\hline Sengul and Gjorv [37] (2008) & 0.99 \\
Sengul and Gjorv [8] (2009) & 0.99 \\
Spratt et al. [39] (2011) & 0.9986 \\
Ghosh and Tran [61] (2015) & $0.82-0.95$ \\
Gudimettla and Crawford [53] & 0.98 \\
(2016) & 0.979 \\
Authors' work (2016)
\end{tabular}

immersed structures have been studied by Presuel-Moreno et al. [65].

\section{Summary and Conclusions}

Through an extensive literature review, this paper identifies several factors which might have potential influence on the electrical resistivity of concrete. Effect of each parameter is briefly summarized below.

(i) In agreement with most studies, when there is an embedded rebar in the concrete, the electrical current field is distorted, and thus errors can result in the electrical resistivity measurements. To minimize this effect, it is suggested to place all electrodes perpendicular to the embedded rebar on the concrete surface and take at least five measurements, each a few millimetres in distance from one another. Also, a correction factor should be applied to resistivity measurements once rebar is present in concrete. However, effect of rebar presence on the resistivity measurements is well-understood; just a few studies could be found to identify the rebar presence effect and more field investigations are still needed in this area.

(ii) Presence of cracks in concrete was also identified as an influential parameter on electrical resistivity since it is initially presumed that concrete is homogenous, isotropic, and uncracked. Depth of crack, orientation of probes on crack, and type of crack (conductive or isolated) can individually affect the resistivity readings. As suggested for embedded rebar in the concrete, all electrodes should be placed in perpendicular direction to cracks. It was reported that higher resistivity readings were obtained from conductive cracks whereas lower resistivity values were gained for insulated cracks. However, no information is provided to show how much cracking induced by corrosion influences concrete resistivity. In addition when both insulated and conductive cracks are bridged together, their integrated influence on electrical resistivity is not well-understood.

(iii) The moisture state and temperature of concrete during resistivity measurements were also found to be of major influence on recorded data. As temperature increases, the ions mobility becomes faster; consequently, electrical conductivity of concrete also increases. To lessen the temperature effect on resistivity results, no practical correlation is still published for real-world conditions. Essentially, electrical resistivity reduces with an increase in moisture content as a result of changing in the ion movement. It is strongly recommended to take resistivity measurements when concrete is in Saturated Surface Dry (SSD) condition. Yet, more investigations are required to understand how much time is needed for water to infiltrate the concrete to obtain constant moisture level through the bulk sample. 
(iv) The studies related to resistivity measurement test device confirmed that electrical signal shape and frequency, electrode contact with concrete surface, and probe spacing of surface resistivity measurement device can affect the resistivity results. To minimize the effect of signal shape and frequency, using low frequency range square-wave signal for surface resistivity and high frequency range for bulk resistivity is recommended. Proper contact should also be provided to not mislead resistivity readings. Using a saturated sponge between electrodes and concrete surface can reduce this effect. In 4-point Wenner probe method, as it is assumed that concrete is homogenous material, aggregates inside concrete also affect its homogeneity due to their higher resistivity. Therefore, providing enough wide spaces between electrodes is essential to diminish aggregates effect. As a rule of thumb, probe spacing 1.5 times higher than the maximum aggregate size should be considered.

(v) Aggregate content and type were identified to have an influence on concrete resistivity. Increase in aggregate content results in higher resistivity values due to their less porosity and lower electrical conductivity. Also, aggregates with rough surface texture were found to have higher resistivity as their tortuosity is higher. Therefore, the effect of aggregates content and type should be accounted for in resistivity measurements.

(vi) Carbonation process in aged concrete forms a multilayered system that results in various resistivity values through the concrete depth. So, its effect should be mitigated during resistivity measurements. Lower resistivity is also generated when $\mathrm{w} / \mathrm{b}$ ratio is high due to higher percentage of porosity.

Correlation between concrete electrical resistivity and its certain durability characteristics such as chloride diffusivity, compressive strength, and corrosion potential/rate was discussed in this paper and is summarized below.

(i) Concrete resistivity is inversely related to chloride ingress, where lower resistivity indicated the area where chloride diffusion will be faster. A retardation of chloride can be taken into account through the introduced reaction factor $\left(r_{\mathrm{cl}}\right)$. More research is still required to better simulate sea site conditions.

(ii) Furthermore, a strong correlation can be found between increasing electrical resistivity of concrete and the corrosion rate. The relationship can be seen when corrosion has initiated (active conditions). It will not be valid in the case of saturated concrete, where although the resistivity is low, the corrosion rate will be small because of lack of oxygen. Field data was considered in just a few investigations and, thus, it is of high interest to gather more field experience.

(iii) In addition, concrete compressive strength and its electrical resistivity have a direct relationship with each other as both directly depend on the porosity of the matrix at early age. However, at a later age, the conductivity of the pore solution and the degree of concrete saturation both influence this relationship. No practical relationship was identified in the literatures between compressive strength and electrical resistivity.

(iv) Four common measurement electrode geometries that have been employed in several studies to conduct electrical test on cementitious cylinders were introduced in this article. Among them, a strong direct linear correlation between two common methods of resistivity measurements (concrete surface and bulk resistivity) was presented. However, more attention should be paid to multilayered cementitious composite systems in the field as electrical current flows differently in these two techniques and for the types of layered electrical properties that can happen because of moisture gradients, chemical changes, and ionic gradients.

$\begin{array}{ll}\text { Abbreviations } \\ \text { CON: } & \text { Concrete } \\ \text { CEM: } & \text { Cement paste } \\ \text { MOR: } & \text { Mortar } \\ \text { MK: } & \text { Metakaolin } \\ \text { SF: } & \text { Silica fume } \\ \text { RHA: } & \text { Rice Husk Ash } \\ \text { OPC: } & \text { Ordinary Portland Cement } \\ \text { SLG: } & \text { Slag } \\ \text { FA: } & \text { Fly ash } \\ \text { NP: } & \text { Natural pozzolan } \\ \text { UPV: } & \text { Ultrasonic Pulse Velocity } \\ \text { WPC: } & \text { White Portland Cement } \\ \text { PFA: } & \text { Pulverized-Fuel Ash } \\ \text { MS: } & \text { Microsilica } \\ \text { LPR: } & \text { Linear Polarization Resistance technique } \\ \text { TNVM: } & \text { Total Number of Various Mixtures } \\ \text { w/b: } & \text { Water/binder ratio } \\ \text { NR: } & \text { Not reported } \\ \text { CR: } & \text { Counter electrode } \\ \text { RE: } & \text { Reference electrode } \\ \text { SC: } & \text { Slag cement } \\ \text { CA: } & \text { Crystalline admixtures } \\ \text { PLC: } & \text { Portland Limestone Cement. } \\ & \end{array}$

\section{Conflicts of Interest}

The authors declare that there are no conflicts of interest regarding the publication of this paper.

\section{References}

[1] P. K. Mehta and P. J. M. Monteiro, Concrete: microstructure, properties, and materials, McGraw-Hill, New York, NY, USA, 3rd edition, 2006.

[2] ASTM, "Standard test method for bulk electrical conductivity of hardened concrete," ASTM C1760-12, ASTM International, 2012. 
[3] AASHTO, "Method of test for surface resistivity indication of concrete's ability to resist chloride ion penetration," AASHTO TP 95, Am. Assoc. State Highw. Transp. Off., 2011.

[4] O. Sengul, "Use of electrical resistivity as an indicator for durability," Construction and Building Materials, vol. 73, pp. 434-441, 2014.

[5] F. Rajabipour, J. Weiss, and D. M. Abraham, "Insitu electrical conductivity measurements to assess moisture and ionic transport in concrete (A discussion of critical features that influence the measurements)," in Proceedings of the International RILEM Symposium on Concrete Science and Engineering: A Tribute to Arnon Bentur, 2004.

[6] H. Layssi, P. Ghods, A. R. Alizadeh, and M. Salehi, "Electrical resistivity of concrete," Concrete International, pp. 41-46, 2015.

[7] R. B. Polder, "Test methods for on site measurement of resistivity of concrete-a RILEM TC-154 technical recommendation," Construction and Building Materials, vol. 15, no. 2-3, pp. 125-131, 2001.

[8] O. Sengul and O. E. Gjorv, "Effect of embedded steel on electrical resistivity measurements on concrete structures," $A C I$ Materials Journal, vol. 106, no. 1, 2009.

[9] M. Salehi, P. Ghods, and O. Burkan Isgor, "Numerical investigation of the role of embedded reinforcement mesh on electrical resistivity measurements of concrete using the Wenner probe technique," Materials and Structures, vol. 49, no. 1-2, pp. 301-316, 2016.

[10] J. F. Lataste, C. Sirieix, D. Breysse, and M. Frappa, "Electrical resistivity measurement applied to cracking assessment on reinforced concrete structures in civil engineering," NDT \& $E$ International, vol. 36, no. 6, pp. 383-394, 2003.

[11] N. Wiwattanachang and P. H. Giao, "Monitoring crack development in fiber concrete beam by using electrical resistivity imaging," Journal of Applied Geophysics, vol. 75, no. 2, pp. 294304, 2011.

[12] K. Hornbostel, C. K. Larsen, and M. R. Geiker, "Relationship between concrete resistivity and corrosion rate-a literature review," Cement and Concrete Composites, vol. 39, pp. 60-72, 2013.

[13] D. A. Whitting and M. A. Nagi, Electrical Resistivity of Concrete, Portland Cement Association, Skokie, Ill, USA, 2003.

[14] RILEM TC 154-EMC, "Recommendations of RILEM TC 154EMC: electrochemical techniques for measuring metallic corrosion half-cell potential measurements-potential mapping on reinforced concrete structures," Materials and Structures, vol. 36, no. 261, pp. 461-471, 2003.

[15] F. Wenner, "A method of measuring earth resistivity," Bulletin of the Bureau of Standards, vol. 12, no. 4, pp. 469-478, 1916.

[16] R. Ranade, J. Zhang, J. P. Lynch, and V. C. Li, "Influence of micro-cracking on the composite resistivity of Engineered Cementitious Composites," Cement and Concrete Research, vol. 58, pp. 1-12, 2014.

[17] K. R. Gowers and S. G. Millard, "Measurement of concrete resistivity for assessment of corrosion severity of steel using wenner technique," ACI Materials Journal, vol. 96, no. 5, 1999.

[18] W. Morris, E. I. Moreno, and A. A. Sagüés, "Practical evaluation of resistivity of concrete in test cylinders using a Wenner array probe," Cement and Concrete Research, vol. 26, no. 12, pp. 1779$1787,1996$.

[19] A. Bentur, S. Diamond, and B. N. Steven, Steel Corrosion in Concrete: Fundamentals and Civil Engineering Practice, EFN Spon, London, UK, 1st edition, 1997.
[20] L. Sadowski, "Methodology for assessing the probability of corrosion in concrete structures on the basis of half-cell potential and concrete resistivity measurements," The Scientific World Journal, vol. 2013, Article ID 714501, 8 pages, 2013.

[21] R. Spragg, C. Villani, J. Weiss et al., "Surface and uniaxial electrical measurements on layered cementitious composites having cylindrical and prismatic geometries," in Proceedings of the International Conference on the Durability of Concrete Structures, West Lafayette, Ind, USA, 2014.

[22] D. P. Bentz, K. A. Snyder, and A. Ahmed, "Anticipating the setting time of high-volume fly ash concretes using electrical measurements: feasibility studies using pastes," Journal of Materials in Civil Engineering, vol. 27, no. 3, Article ID 4014129, 2015.

[23] R. Weydert and C. Gehlen, "Electrolytic resistivity of cover concrete: relevance, measurement and interpretation," in Proceedings of CIB W078 Workshop on Information Technology in Construction, Rotterdam, Netherlands, 1999.

[24] F. Presuel-Moreno, Y. Liu, and M. Paredes, Understanding the Effect of Rebar Presence and/or Multilayered Concrete Resistivity on the Apparent Surface Resistivity Measured via the Four Point Wenner Method, NACE International, 2009.

[25] C.-T. Chen, J.-J. Chang, and W.-C. Yeih, "The effects of specimen parameters on the resistivity of concrete," Construction and Building Materials, vol. 71, pp. 35-43, 2014.

[26] A. J. Garzon, J. Sanchez, C. Andrade, N. Rebolledo, E. Menéndez, and J. Fullea, "Modification of four point method to measure the concrete electrical resistivity in presence of reinforcing bars," Cement and Concrete Composites, vol. 53, pp. 249-257, 2014.

[27] Y.-C. Lim, T. Noguchi, and C.-G. Cho, "A quantitative analysis of the geometric effects of reinforcement in concrete resistivity measurement above reinforcement," Construction and Building Materials, vol. 83, pp. 189-193, 2015.

[28] W. Morris, A. Vico, and M. Vázquez, "Chloride induced corrosion of reinforcing steel evaluated by concrete resistivity measurements," Electrochimica Acta, vol. 49, no. 25, pp. 44474453, 2004.

[29] U. M. Angst and B. Elsener, "On the applicability of the wenner method for resistivity measurements of concrete," ACI Materials Journal, vol. 111, no. 6, pp. 661-672, 2014.

[30] M. Goueygou, O. Abraham, and J.-F. Lataste, "A comparative study of two non-destructive testing methods to assess nearsurface mechanical damage in concrete structures," NDT and E International, vol. 41, no. 6, pp. 448-456, 2008.

[31] T. Rupnow and P. Icenogle, "Evaluation of surface resistivity measurements as an alternative to the rapid chloride permeability test for quality assurance and acceptance," Tech. Rep. 2290, Performing Organization Name and Address Louisiana Transportation Research Center, Baton Rouge, La, USA, 2012.

[32] F. Presuel-Moreno and Y. Liu, "Temperature effect on electrical resistivity measurements on mature saturated concrete," in Proceedings of the NACE-International Corrosion Conference Series 7, Salt Lake City, Utah, USA, 2012.

[33] R. Van Noort, M. Hunger, and P. Spiesz, "Long-term chloride migration coefficient in slag cement-based concrete and resistivity as an alternative test method," Construction and Building Materials, vol. 115, pp. 746-759, 2016.

[34] A. Lübeck, A. L. G. Gastaldini, D. S. Barin, and H. C. Siqueira, "Compressive strength and electrical properties of concrete with white Portland cement and blast-furnace slag," Cement and Concrete Composites, vol. 34, no. 3, pp. 392-399, 2012. 
[35] J. Su, C. Yang, W. Wu, and R. Huang, "Effect of moisture content on concrete resistivity measurement," Journal of the Chinese Institute of Engineers, vol. 25, no. 1, pp. 117-122, 2002.

[36] M. Saleem, M. Shameem, S. E. Hussain, and M. Maslehuddin, "Effect of moisture, chloride and sulphate contamination on the electrical resistivity of Portland cement concrete," Construction and Building Materials, vol. 10, no. 3, pp. 209-214, 1996.

[37] O. Sengul and O. E. Gjorv, "Electrical resistivity measurements for quality control during concrete construction," ACI Materials Journal, vol. 105, no. 6, 2008.

[38] M. D. Newlands, M. R. Jones, S. Kandasami, and T. A. Harrison, "Sensitivity of electrode contact solutions and contact pressure in assessing electrical resistivity of concrete," Materials and Structures, vol. 41, no. 4, pp. 621-632, 2008.

[39] R. Spratt, J. Castro, T. Nantung, E. Paredes, and W. J. Weiss, "Variability Analysis of the Bulk Resistivity Measured Using Concrete Cylinders," Tech. Rep., Purdue University Press, West Lafayette, Ind, USA, 2011.

[40] J. W. McCarter, G. Starrs, S. Kandasami, M. R. Jones, and M. Chrisp, "Electrode configurations for resistivity measurements on concrete," ACI Materials Journal, vol. 106, no. 3, 2009.

[41] Y. Liu and F. J. Presuel-Moreno, "Normalization of temperature effect on concrete resistivity by method using Arrhenius law," ACI Materials Journal, vol. 111, no. 4, pp. 433-442, 2014.

[42] J. W. Bryant Jr., R. E. Weyers, and J. M. Garza, "In-place resistivity of bridge deck concrete mixtures," ACI Materials Journal, vol. 106, no. 2, 2009.

[43] R. Spragg, C. Villani, K. Snyder, D. Bentz, J. Bullard, and J. Weiss, "Factors that influence electrical resistivity measurements in cementitious systems," Journal of the Transportation Research Board, vol. 2342, pp. 90-98, 2013.

[44] Y. Liu and F. Presuel-Moreno, "Effect of elevated temperature curing on compressive strength and electrical resistivity of concrete with fly ash and GGBS," ACI Materials Journal, vol. 111, no. 5, 2014.

[45] W. J. McCarter, T. M. Chrisp, G. Starrs, P. A. M. Basheer, and J. Blewett, "Field monitoring of electrical conductivity of coverzone concrete," Cement and Concrete Composites, vol. 27, no. 7-8, pp. 809-817, 2005.

[46] K. M. Smith, A. J. Schokker, and P. J. Tikalsky, "Performance of supplementary cementitious materials in concrete resistivity and corrosion monitoring evaluations," ACI Materials Journal, vol. 101, no. 5, 2004.

[47] H. Minagawa and M. Hisada, "Consideration about chloride ion diffusion coefficient estimated by electric resistivity of concrete exposed in tidal zone," in Proceedings of the $3 \mathrm{rd}$ International Conference on Sustainable Construction Materials and Technologies, Kyoto, Japan, 2013.

[48] F. Presuel-Moreno, Y.-Y. Wu, and Y. Liu, "Effect of curing regime on concrete resistivity and aging factor over time," Construction and Building Materials, vol. 48, pp. 874-882, 2013.

[49] E. Güneyisi, T. Özturan, and M. Gesoǧlu, "A study on reinforcement corrosion and related properties of plain and blended cement concretes under different curing conditions," Cement and Concrete Composites, vol. 27, no. 4, pp. 449-461, 2005.

[50] R. B. Polder and W. H. A. Peelen, "Characterisation of chloride transport and reinforcement corrosion in concrete under cyclic wetting and drying by electrical resistivity," Cement and Concrete Composites, vol. 24, no. 5, pp. 427-435, 2002.

[51] T. Y. D. Lim, S. Teng, S. D. Bahador, and O. E. Gjørv, "Durability of very-high-strength concrete with supplementary cementitious materials for marine environments," ACI Materials Journal, vol. 113, no. 1, pp. 95-103, 2016.

[52] R. J. Kessler, R. G. Powers, E. Vivas, M. A. Paredes, and Y. P. Virmani, "Surface resistivity as an indicator of concrete chloride penetration resistance," in Proceedings of the Concrete Bridge Conference, p. 18, 2008.

[53] J. Gudimettla and G. Crawford, "Resistivity tests for concreterecent field experience," ACI Materials Journal, vol. 113, no. 4, 2016.

[54] A. Jenkins, "Surface resistivity as an alternative for rapid chloride permeability test of hardened concrete," Tech. Rep. FHWA-KS-14-15, Kansas Department of Transportation Bureau of Research, Topeka, Kan, USA, 2015.

[55] Y. Liu, F. J. Presuel-Moreno, and M. A. Paredes, "Determination of chloride diffusion coefficients in concrete by electrical resistivity method," ACI Materials Journal, vol. 112, no. 5, pp. 631640, 2015.

[56] A. A. Ramezanianpour, A. Pilvar, M. Mahdikhani, and F. Moodi, "Practical evaluation of relationship between concrete resistivity, water penetration, rapid chloride penetration and compressive strength," Construction and Building Materials, vol. 25, no. 5, pp. 2472-2479, 2011.

[57] P. A. M. Basheer, P. R. V. Gilleece, A. E. Long, and W. J. Mc Carter, "Monitoring electrical resistance of concretes containing alternative cementitious materials to assess their resistance to chloride penetration," Cement and Concrete Composites, vol. 24, no. 5, pp. 437-449, 2002.

[58] D. T. Y. Lim, B. Sabet Divsholi, D. Xu, and S. Teng, "Evaluation of high performance concrete using electrical resistivity technique," in Proceedings of the Our World in Concrete and Structures, Singapore, 2011.

[59] C. Andrade, R. d'Andrea, and N. Rebolledo, "Chloride ion penetration in concrete: the reaction factor in the electrical resistivity model," Cement and Concrete Composites, vol. 47, pp. 41-46, 2014.

[60] W. Morris, A. Vico, M. Vazquez, and S. R. de Sanchez, "Corrosion of reinforcing steel evaluated by means of concrete resistivity measurements," Corrosion Science, vol. 44, no. 1, pp. 81-99, 2002.

[61] P. Ghosh and Q. Tran, "Correlation between bulk and surface resistivity of concrete," International Journal of Concrete Structures and Materials, vol. 9, no. 1, pp. 119-132, 2015.

[62] P. Ghosh and Q. Tran, "Influence of parameters on surface resistivity of concrete," Cement and Concrete Composites, vol. 62, pp. 134-145, 2015.

[63] A. L. G. Gastaldini, G. C. Isaia, T. F. Hoppe, F. Missau, and A. P. Saciloto, "Influence of the use of rice husk ash on the electrical resistivity of concrete: a technical and economic feasibility study," Construction and Building Materials, vol. 23, no. 11, pp. 3411-3419, 2009.

[64] C. Andrade, M. Castellote, and R. D’Andrea, "Measurement of ageing effect on chloride diffusion coefficients in cementitious matrices," Journal of Nuclear Materials, vol. 412, no. 1, pp. 209216, 2011.

[65] F. Presuel-Moreno, A. Suares, and Y. Liu, Characterization of New and Old Concrete Structures Using Surface Resistivity Measurements, Florida Department of Transportation, Dania Beach, Fla, USA, 2010.

[66] H.-W. Song and V. Saraswathy, "Corrosion monitoring of reinforced concrete structures-a review," International Journal of Electrochemical Science, vol. 2, pp. 1-28, 2007. 
[67] W. Elkey and E. J. Sellevold, Electrical Resistivity of Concrete, supplement 80, Norwegian Road Research Laboratory, Oslo, Norway, 1995.

[68] “Operating Instructions Resipod Family Manual.” Proceq.

[69] SURF ${ }^{\mathrm{TM}}$, Surface Electrical Resistivity of Concrete Manual, Giatec Scientific Inc., https://www.giatecscientific.com/concrete-resistivity/surf/.

[70] J. Weiss, K. Snyder, J. Bullard, and D. Bentz, "Using a saturation function to interpret the electrical properties of partially saturated concrete," Journal of Materials in Civil Engineering, vol. 25, no. 8, pp. 1097-1106, 2013.

[71] S. G. Millard, "Reinforced concrete resistivity measurement techniques," Institution of Civil Engineers, vol. 91, pp. 71-88, 1991.

[72] F. Presuel-Moreno, Y. Liu, and Y.-Y. Wu, "Numerical modeling of the effects of rebar presence and/or multilayered concrete resistivity on the apparent resistivity measured via the Wenner method," Construction and Building Materials, vol. 48, pp. 1625, 2013.

[73] M. Salehi, Numerical investigation of the role of embedded reinforcement mesh on electrical resistivity measurements of concrete using the Wenner probe technique [M.S. thesis], Carleton University, Ottawa, Canada, 2013.

[74] J. Sanchez, C. Andrade, J. Torres, N. Rebolledo, and J. Fullea, "Determination of reinforced concrete durability with on-site resistivity measurements," Materials and Structures, vol. 50, no. $1,2017$.

[75] M. Morales, "Experimental investigation of the effects of embedded rebar, cracks, chloride ingress and corrosion on electrical resistivity measurements of reinforced concrete," Master, Oregon State University, 2015.

[76] A. A. Shah and Y. Ribakov, "Non-destructive measurements of crack assessment and defect detection in concrete structures," Materials and Design, vol. 29, no. 1, pp. 61-69, 2008.

[77] M. Chouteau and S. Beaulieu, "An investigation on application of the electrical resistivity tomography method to concrete structures," in Proceedings of the Geophysics 2002. The 2nd Annual Conference on the Application of Geophysical and NDT Methodologies to Transportation Facilities and Infrastructure, Washington DC, USA, 2002.

[78] E. Taillet, J. F. Lataste, P. Rivard, and A. Denis, "Non-destructive evaluation of cracks in massive concrete using normal $\mathrm{dc}$ resistivity logging," NDT and E International, vol. 63, pp. 11-20, 2014.

[79] M. Salehi, P. Ghods, and O. B. Isgor, "Numerical study on the effect of cracking on surface resistivity of plain and reinforced concrete elements," Journal of Materials in Civil Engineering, vol. 27, no. 12, Article ID 04015053, 2015.

[80] A. J. Ewins, "Resistivity Measurements in Concrete," British Journal of NDT, vol. 32, no. 3, pp. 120-126, 1990.

[81] R. Henkensiefken, J. Castro, D. Bentz, T. Nantung, and J. Weiss, "Water absorption in internally cured mortar made with waterfilled lightweight aggregate," Cement and Concrete Research, vol. 39, no. 10, pp. 883-892, 2009.

[82] M. D. A. Thomas, “The use of conductive gel," 2008.

[83] J. D. Shane, Electrical conductivity and transport properties of cement-based material measured by impedance spectroscopy [ph.D. thesis], Nothwestern University, Evanston, Ill, USA, 2000.

[84] R. Spragg, Y. Bu, K. Snyder, D. Bentz, and J. Weiss, "Electrical testing of cement-based materials: role of testing techniques, sample conditioning," Tech. Rep. FHWA/IN/JTRP-2013/28, Purdue University, 2013.
[85] A. Shahroodi, Development of test methods for assessment of concrete durability for use in performance-based specifications [M.S. thesis], University of Toronto, Toronto, Canada, 2010.

[86] J. M. S. Marquez, Influence of saturation and geometry on surface electrical resistivity measurements [M.S. thesis], Concorida University, Montreal, Canada, 2015.

[87] M. Castellote, C. Andrade, and M. C. Alonso, "Standardization, to a reference of $25^{\circ} \mathrm{C}$, of electrical resistivity for mortars and concretes in saturated or isolated conditions," ACI Materials Journal, vol. 99, no. 2, 2002.

[88] Y. A. Villagrán Zaccardi, J. F. García, P. Huélamo, and Á. A. Di Maio, "Influence of temperature and humidity on Portland cement mortar resistivity monitored with inner sensors," Materials and Corrosion, vol. 60, no. 4, pp. 294-299, 2009.

[89] S. Poyet, "Experimental investigation of the effect of temperature on the first desorption isotherm of concrete," Cement and Concrete Research, vol. 39, no. 11, pp. 1052-1059, 2009.

[90] S. G. Millard, J. A. Harrison, and K. R. Gowers, "Practical measurement of concrete resistivity," British Journal NonDestructive Testing, vol. 33, pp. 59-63, 1991.

[91] T. M. Chrisp, G. Starrs, W. J. McCarter, E. Rouchotas, and J. Blewett, "Temperature-conductivity relationships for concrete: an activation energy approach," Journal of Materials Science Letters, vol. 20, no. 12, pp. 1085-1087, 2001.

[92] DuraCrete R17, "Probabilistic performance based durability design of concrete structures, includes general guidelines for durability design and redesign," Tech. Rep. BE95-1347/R17, The European Union - Brite EuRam III, CUR, Gouda.

[93] M. Pour-Ghaz, O. B. Isgor, and P. Ghods, "The effect of temperature on the corrosion of steel in concrete. Part 1: Simulated polarization resistance tests and model development," Corrosion Science, vol. 51, no. 2, pp. 415-425, 2009.

[94] C. K. Larsen, E. J. Sellevold, J.-M. Østvik, and Ø. Vennesland, "Electrical resistivity of concrete-Part II: influence of moisture content and temperature," in Proceedings of the 2nd International RILEM Symposium on Advances in Concrete through Science and Engineering, 2006.

[95] Y. Liu, Accelerated curing of concrete with high volume pozzolans -resistivity, diffusivity and compressive strength [ph.D. thesis], Florida Atlantic University, Boca Raton, Fla, USA, 2012.

[96] X. Lu, "Application of the Nernst-Einstein equation to concrete," Cement and Concrete Research, vol. 27, no. 2, pp. 293-302, 1997.

[97] K. R. Backe, O. B. Lile, and S. K. Lyomov, "Characterizing curing cement slurries by electrical conductivity," SPE Drilling and Completion, vol. 16, no. 4, pp. 201-207, 2001.

[98] FDOT, "Florida Method of Test For Concrete Resistivity as an Electrical Indicator of its Permeability," FM 5-578, 2004.

[99] R. J. Kessler, R. G. Powers, and M. A. Paredes, "Resistivity measurements of water saturated concrete as an indicator of permeability," in Proceedings of the Corrosion, Houston, Tex, USA.

[100] ASTM, "Standard test method for electrical indication of concrete's ability to resist chloride ion penetration," ASTM International C1202-12, 2012.

[101] R. K. Dhir, M. J. McCarthy, and M. D. Newlands, Eds., Challenges of Concrete Construction: Concrete for Extreme Conditions: Proceedings of the International Conference held at the University of Dundee, on 9-11 September 2002, vol. 6, Thomas Telford Publishing, Scotland, UK.

[102] E. Vivas, A. Boyd, and H. R. Hamilton III, "Permeability of concrete-comparison of conductivity and diffusion methods," 
Tech. Rep. 49104504 992-12 (0026899), Florida Department of Transportation, Tallahassee, Fla, USA, 2007.

[103] G. K. Glass, C. L. Page, and N. R. Short, "Factors affecting the corrosion rate of steel in carbonated mortars," Corrosion Science, vol. 32, no. 12, pp. 1283-1294, 1991.

[104] L. Bertolini and R. Polder, Concrete resistivity and reinforcement corrosion rate as a function of temperature and humidity of the environment TNO 97-NaN-R0574, Netherlands Organisation for Applied Scientific Research, Delft, The Netherlands, 1997.

[105] ASTM, "Test Method for Corrosion Potentials of Uncoated Reinforcing Steel in Concrete," ASTM International C876, 2015.

[106] N. J. Carino, "Nondestructive techniques to investigate corrosion status in concrete structures," Journal of Performance of Constructed Facilities, vol. 13, no. 3, pp. 96-106, 1999.

[107] N. Gucunski, F. Romero, S. Kruschwitz, R. Feldmann, A. Abu-Hawash, and M. Dunn, "Multiple complementary nondestructive evaluation technologies for condition assessment of concrete bridge decks," Transportation Research Record: Journal of the Transportation Research Board, no. 2201, pp. 34-44, 2010.

[108] N. Gucunski, A. Imani, F. Romero et al., Nondestructive testing to identify concrete bridge deck deterioration, Transportation Research Board, Washington DC, USA, 2012.

[109] C. Alonso, C. Andrade, and J. A. González, "Relation between resistivity and corrosion rate of reinforcements in carbonated mortar made with several cement types," Cement and Concrete Research, vol. 18, no. 5, pp. 687-698, 1988.

[110] C. Andrade and C. Alonso, "Corrosion rate monitoring in the laboratory and on-site," Construction and Building Materials, vol. 10, no. 5, pp. 315-328, 1996.

[111] J. Gulikers, “Theoretical considerations on the supposed linear relationship between concrete resistivity and corrosion rate of steel reinforcement," Materials and Corrosion, vol. 56, no. 6, pp. 393-403, 2005.

[112] C. Andrade and C. Alonso, "Test methods for on-site corrosion rate measurement of steel reinforcement in concrete by means of the polarization resistance method," RILEM, vol. 37, pp. 623643, 2004.

[113] E. Vesikari and M.-K. Soderqvist, "Life cycle management of concrete infrastructures for improved sustainability," in Proceedings of the 9th International Bridge Management Conference, pp. 15-28, 2003.

[114] R. Gupta and A. Biparva, "Innovative test technique to evaluate 'self-sealing' of concrete," Journal of Testing and Evaluation, vol. 43, no. 5, pp. 1091-1098, 2015.

[115] R. Gupta and A. Biparva, "Do crystalline water proofing admixtures affect restrained plastic shrinkage behavior of concrete?" Revista ALCONPAT, vol. 7, no. 1, p. 15, 2017. 

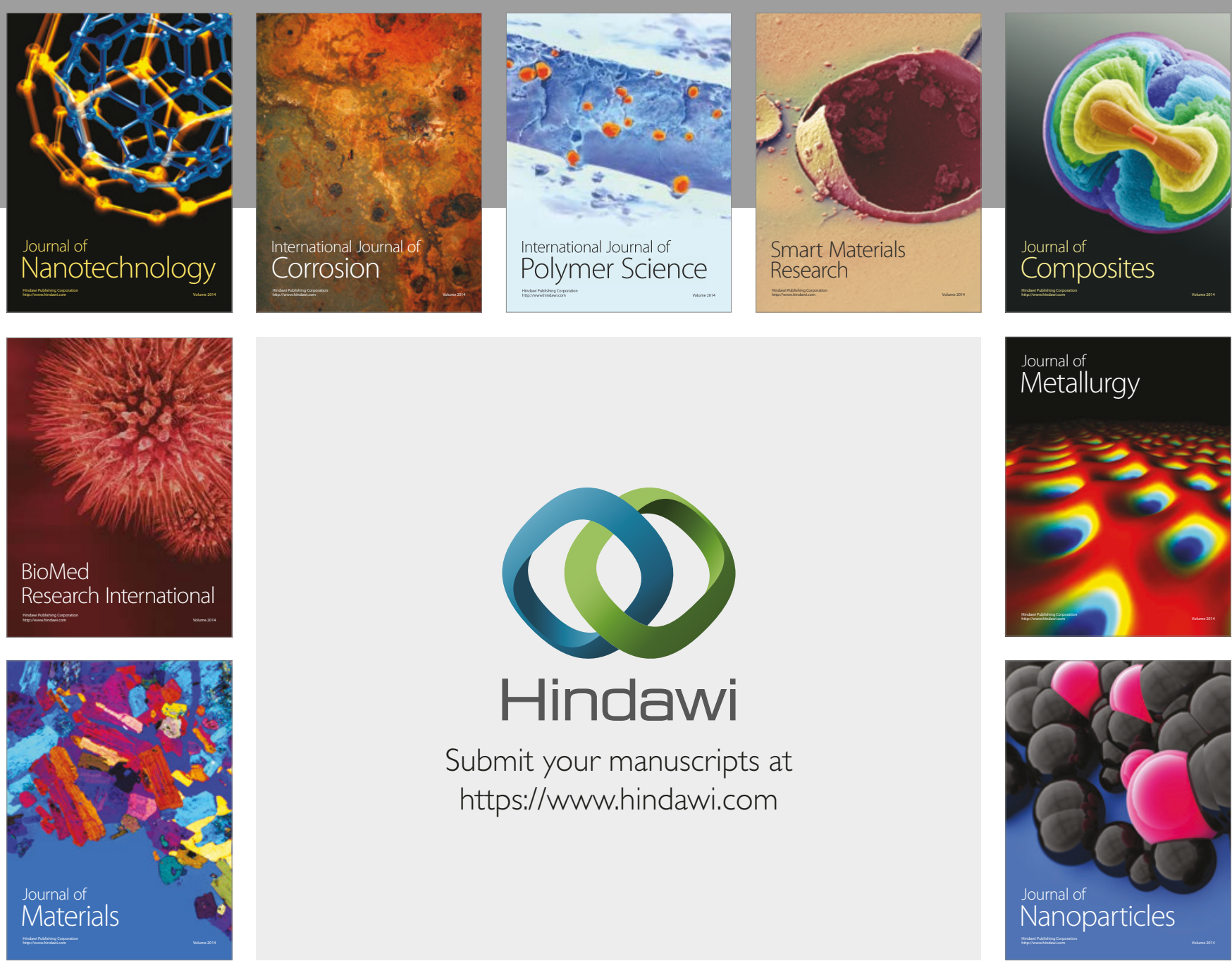

\section{Hindawi}

Submit your manuscripts at

https://www.hindawi.com
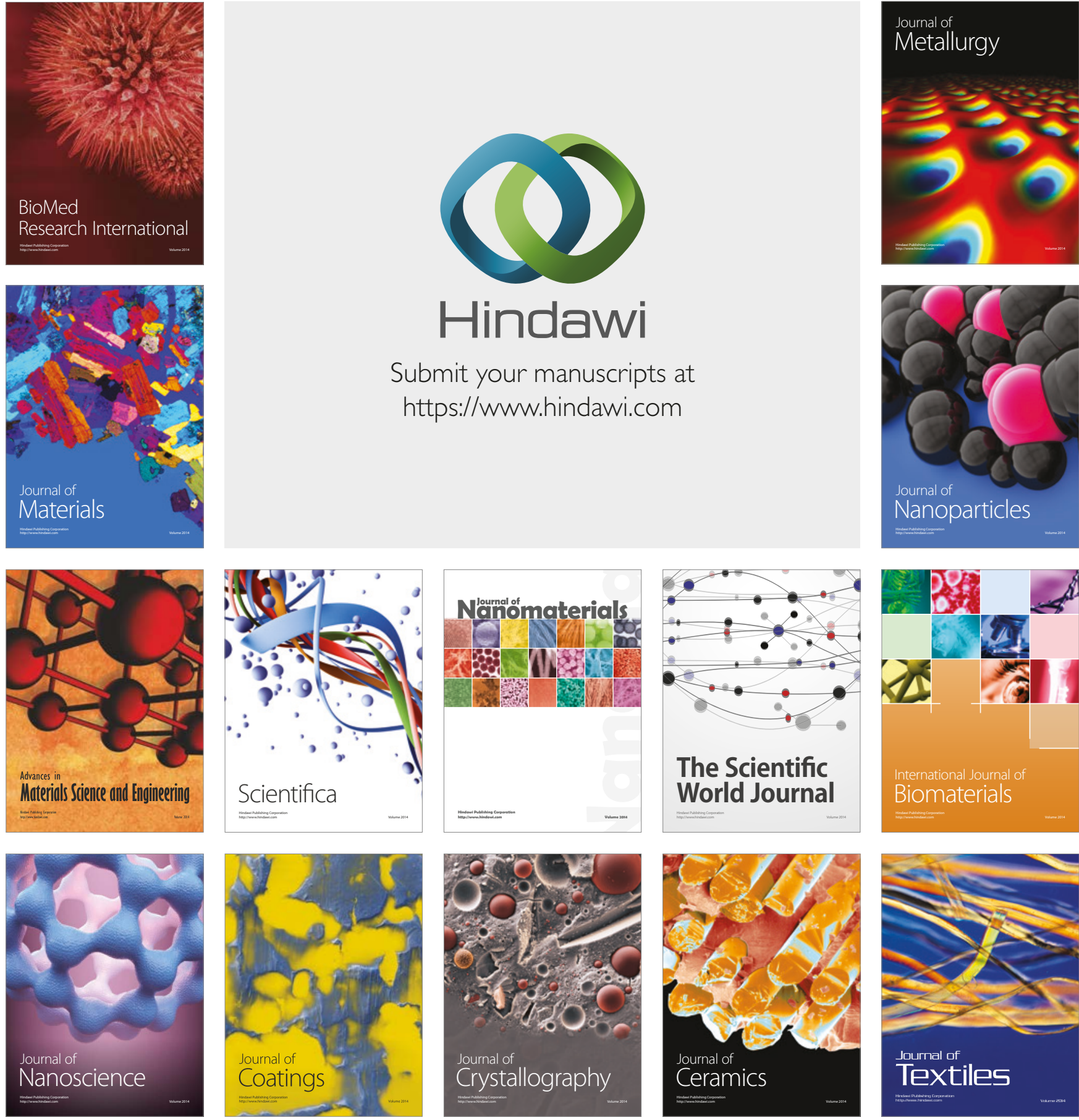

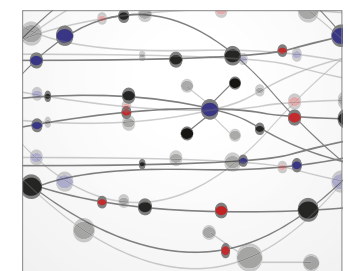

The Scientific World Journal
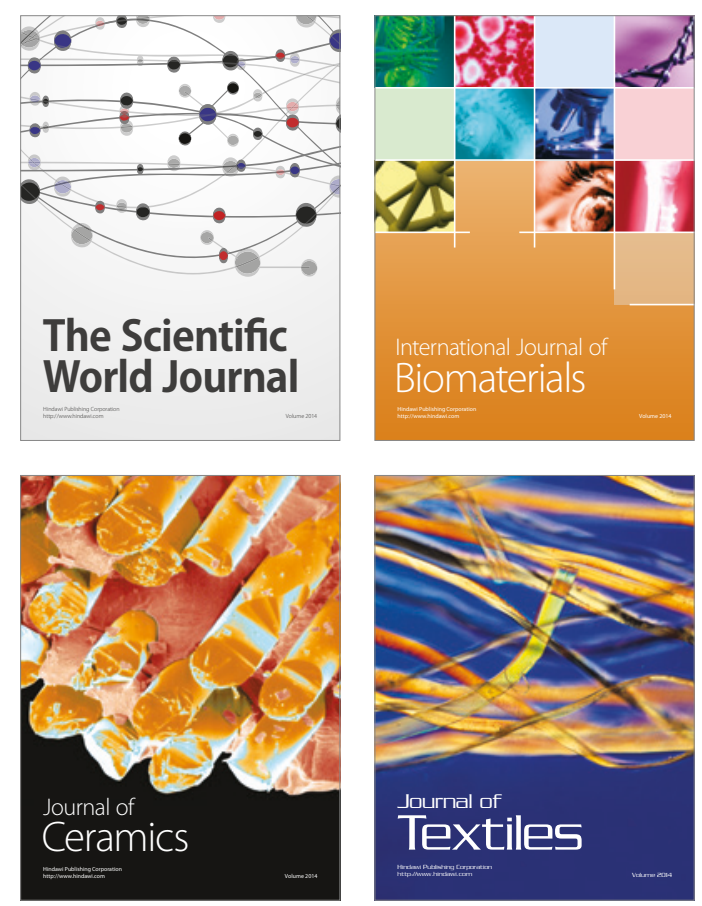